\title{
Characteristics of pulsed plasma doping sources for ultrashallow junction formation
}

\author{
Ankur Agarwal ${ }^{\mathrm{a})}$ \\ Department of Chemical and Biomolecular Engineering, University of Illinois, Urbana, Illinois 61801 \\ Mark J. Kushner ${ }^{\text {b) }}$ \\ Department of Electrical and Computer Engineering, Iowa State University, 104 Marston Hall, Ames, \\ Iowa 50011-2151
}

(Received 24 September 2006; accepted 28 November 2006; published online 23 March 2007)

\begin{abstract}
Plasma doping of semiconductors is being investigated for low energy ion implantation to form ultrashallow junctions. In plasma doping, ions are extracted from a quasicontinuous plasma using a pulsed bias on the substrate. Plasma-based implantation techniques have the potential for higher throughput than those attainable with conventional accelerator beamlines due to the higher current densities possible with plasma sources. In this work, results from a computational investigation of plasma sources for doping of semiconductors will be discussed. An inductively coupled plasma (ICP) was used to generate ions at pressures of a few to tens of millitorr. A pulsed bias up to $-20 \mathrm{kV}$ having lengths of tens of microseconds was applied to the substrate to accelerate the ions. Results are presented for $\mathrm{Ar} / \mathrm{NF}_{3}$ gas mixtures which serve as surrogates for the $\mathrm{Ar} / \mathrm{BF}_{3}$ mixtures that would provide boron doping. The consequences of bias voltage waveform, ICP power, operating pressure, and aspect ratio of the reactor on discharge characteristics and ion energy and angular distributions (IEADs) to the substrate will be discussed. The shape of the bias waveform has important consequences on the IEADs not only because of the transit times of the ions but also due to the instabilities that may be launched into the plasma. The aspect ratio of the reactor influences the angular uniformity of the IEADs, particularly when using large biases. () 2007 American Institute of Physics. [DOI: 10.1063/1.2433746]
\end{abstract}

\section{INTRODUCTION}

Plasma processing techniques for microelectronics fabrication must now maintain critical dimensions approaching a few nanometers with uniformity of less than a few percent over wafer diameters of $300 \mathrm{~mm} .{ }^{1,2}$ As the characteristic lengths of features in microelectronic devices decrease, so do their depths. For example, the sources and drains in complementary metal oxide semiconductor field effect transistors (CMOSFETs), a standard component of microelectronics, become shallower as the channel length decreases. ${ }^{3}$ Ultrashallow junctions (USJs) having depths of less than $35 \mathrm{~nm}$ are required for transistors having channel lengths of $<100 \mathrm{~nm}$. These junctions are formed by ion implantation into the silicon substrate. ${ }^{4}$ Since the depth of the junction is determined by the energy of the incident ions, formation of USJs require low energy ions, hundreds of $\mathrm{eV}$ to a few $\mathrm{keV}$.

The most straightforward fabrication method for forming USJ is to extend the beamline, accelerator based ion implantation technology used for deep junctions (many tens to hundreds of $\mathrm{keV}$ ) to lower ion energies. Due to space charge induced divergence, low energy ion beams usually operate at lower currents and current densities than used for conventional deep implantations. These lower currents may result in undesirable low throughput. ${ }^{5}$

Several techniques have been proposed to overcome the

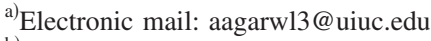

b) Author to whom correspondence should be addressed; electronic mail: mjk@iastate.edu
}

space charge limitations of low energy ion beams. ${ }^{6}$ One method extracts ions from the source and transports them through the beamline at high energies before electrostatically decelerating the ions above the wafer to their final implant energy. ${ }^{7-9}$ This approach has the advantage of maintaining high beam current but may produce a bimodal ion energy distribution on the wafer. ${ }^{6}$ Space charge control can be achieved by increasing the gas pressures within the beam transport path but charge exchange can result in a significant loss of current from the beam. ${ }^{10}$

Several plasma-based techniques have been proposed for fabricating USJs, including pulsed plasma implantation (PPI). ${ }^{11}$ PPI is capable of delivering high ion doses $\left(10^{15} \mathrm{~cm}^{-2}\right)$ at low ion energies (hundreds $\mathrm{eV}$ to many $\mathrm{keV}$ ). In one variation of PPI, a pulsed negative voltage is applied to the wafer to both create a plasma containing the desired dopant species and to accelerate the positive dopant ions from the plasma across the cathode sheath into the wafer. The plasma is ignited with each pulse and extinguishes after each pulse ends. ${ }^{12-16}$ Typical pulse lengths are many to tens of microseconds. For sufficiently low pressures, the ions can collisionlessly traverse the sheath and are implanted into the wafer with energies largely determined by the pulse voltage and the ion charge. By pulsing the bias and allowing the plasma to extinguish, the heat load to the wafer, undesirable etching, and contamination that occur only when the plasma is on are reduced. An alternate configuration for PPI uses an auxiliary plasma source, such as an inductively coupled plasma (ICP). This configuration provides a readily available 
source of ions and reduces concerns associated with restarting the plasma with each pulse. The disadvantage of having the plasma be continually on is possible unwanted production of etching species.

PPI has a few limitations in comparison to beamline implantation. ${ }^{17}$ Unlike beamline implantation there is no systematic ion-mass separation that takes place in PPI. All the positive ions in the plasma can be implanted to some degree. Furthermore, the ions are not strictly monoenergetic as the distribution of ion energies to the substrate depends on gas pressure, pulse shape, and plasma density. ${ }^{18}$ The production of secondary electrons under ion impact for the wide range of implant energies may also be problematic as these electrons can dissipate a significant fraction of the pulse power.

The characteristics of the ion energy and angular distributions (IEADs) incident onto the wafer are critical to determining the junction properties. The IEADs are sensitive functions of the bias voltage waveform and the plasma parameters that determine the sheath properties (e.g. pressure, power, and reactor configuration). Characterizing the consequences of these parameters have on IEADs is important to improve the uniformity, repeatability and reliability, of the implantation process. In this paper, we report on a computational investigation of PPI performed using an auxiliary ICP ion source and a pulsed dc bias on the substrate. The effect of bias waveform, ICP power, pressure, and reactor configuration on pulsed plasma characteristics and IEADs to the wafer will be discussed for an $\mathrm{Ar} / \mathrm{NF}_{3}$ gas mixture, used as a surrogate for $\mathrm{Ar} / \mathrm{BF}_{3}$.

We found that the IEAD is dominantly populated by ions with energies near the bias voltage. A low energy tail of the IEAD can be produced by slowly rising voltage pulses or conditions having thick sheaths where ionization occurs in the sheath. The angular symmetry of the IEAD is, to some degree, controlled by the curvature of the sheath edge. During the pulse, the sheath edge may sample regions of the reactor where the ion density is nonuniform, thereby producing a gradient (or curvature) in the sheath thickness across the wafer. This may result in angular skew to the IEAD.

The model and reaction mechanism are described in Sec. II. Results from the investigation are discussed in Secs. III and IV. Concluding remarks are presented in Sec. V.

\section{DESCRIPTION OF THE MODEL}

The Hybrid Plasma Equipment Model (HPEM) was used to investigate plasma characteristics and reactant fluxes to the substrate in the PPI reactor. The HPEM has been previously described and so will only be briefly discussed here. ${ }^{19,20}$ The HPEM is a two-dimensional simulator which addresses equipment scale plasma chemistry and hydrodynamics, and consists of three main modules. Electromagnetic fields are calculated in the Electromagnetics Module. These fields are then used in the Electron Energy Transport Module (EETM) to obtain electron impact source functions and transport coefficients. In this work, this was accomplished by solving the electron energy equation for the average electron energy of bulk electrons and using a Monte Carlo simulation to follow the trajectories of sheath accelerated secondary electrons. Transport and rate coefficients for the bulk electrons were obtained by solving Boltzmann's equation for the electron energy distribution. These results were then passed to the Fluid Kinetics Module (FKM) in which separate continuity, momentum, and energy equations are solved for each ion and neutral species. A drift diffusion formulation using Scharfetter-Gummel fluxes was used for electrons to enable an implicit solution of the Poisson's equation for the time varying electrostatic potential. Output from the FKM (densities and electrostatic fields) is then transferred to the other modules. This process is iterated until a converged solution is obtained.

The Plasma Chemistry Monte Carlo Module (PCMCM) in the HPEM produces the energy and angular distributions for neutrals and ions striking the wafer surface. The PCMCM launches pseuodoparticles representing ions and neutrals based on the electron impact source functions and the time dependent electric fields obtained from the other modules of the HPEM. Using a Monte Carlo simulation, the PCMCM tracks the trajectories of the ions and neutrals while capturing their gas phase collisions and interactions with the surface using the same reaction mechanism as in the HPEM. Statistics are collected on the energy and angle of pseuodoparticles as they strike specified locations on the surfaces to produce time-averaged energy and angular distributions.

Secondary electron emission by ion impact is an important source of ionization and excitation when large negative voltages are applied to the substrate and the emitted electrons are accelerated to hundreds or thousands of $\mathrm{eV}$ through the sheath. For most surfaces the secondary electron yield per ion, $\gamma$, is a function of the material and ion but otherwise nearly independent of ion energies below a few hundred $\mathrm{eV}$. However, $\gamma$ can significantly increase with higher incident ion energies as well as vary with the condition of the surface. ${ }^{21-25}$ As such $\gamma$ may not remain a constant during the voltage pulse as the sheath potential changes and the incident ion energies change. To account for this likelihood we approximated for ion energy, $E,{ }^{26}$

$$
\begin{aligned}
\gamma(E) & =\gamma_{o}, \quad E<E_{o} \\
& =\gamma_{o}+\frac{d \gamma}{d E}\left(E-E_{o}\right), \quad E \geqslant E_{o},
\end{aligned}
$$

where $\gamma_{o}, E_{o}$, and $d \gamma / d E$ can be functions of the incident ion energy and material. In this investigation we used $\gamma_{o}=0.15$, $E_{o}=3000 \mathrm{eV}$, and $d \gamma / d E=0.75 \times 10^{-3} \mathrm{eV}^{-1}$ for all ions.

The $\mathrm{Ar} / \mathrm{NF}_{3}$ reaction mechanism and species used in this study are listed in Table $\mathrm{I}_{\text {. }} \mathrm{NF}_{3}$ was used as a surrogate for $\mathrm{BF}_{3}$ as would be used in actual plasma doping. This choice was made based on the more reliable database for electron impact and heavy particle reactions available for $\mathrm{NF}_{3}$ compared to $\mathrm{BF}_{3}$. Both gases are highly attaching at low electron energies and have similar inelastic thresholds. As such, for the scaling studies performed here, similar trends are expected for systems using $\mathrm{BF}_{3}$. Rate coefficients for gas phase chemistry were taken from independent studies in the literature $^{32}$ or estimated from measurements for related species. ${ }^{71}$ All pertinent electron impact events which affect 
TABLE I. Ar/ $\mathrm{NF}_{3}$ reaction mechanism.

\begin{tabular}{|c|c|c|}
\hline \multicolumn{3}{|l|}{ Species } \\
\hline e & $\mathrm{NF}_{3}$ & $\mathrm{~N}$ \\
\hline $\mathrm{Ar}$ & $\mathrm{NF}_{3}^{+}$ & $\mathrm{N}^{*}$ \\
\hline $\operatorname{Ar}^{*}$ & $\mathrm{NF}_{2}$ & $\mathrm{~N}^{+}$ \\
\hline $\mathrm{Ar}^{+}$ & $\mathrm{NF}_{2}^{+}$ & $\mathrm{F}_{2}$ \\
\hline $\mathrm{N}_{2}$ & NF & $\mathrm{F}_{2}^{+}$ \\
\hline $\mathrm{N}_{2}^{*}$ & $\mathrm{NF}^{+}$ & $\mathrm{F}$ \\
\hline $\mathrm{N}_{2}^{+}$ & $M$ & $\mathrm{~F}^{-}$ \\
\hline & & $\mathrm{F}^{+}$ \\
\hline Reaction & Rate coefficient ${ }^{\mathrm{a}}$ & Reference \\
\hline$e+\mathrm{Ar} \rightarrow \mathrm{Ar}+e$ & $\mathrm{~b}$ & 27 \\
\hline$e+\mathrm{Ar} \leftrightarrow \mathrm{Ar}^{*}+e$ & $b-d$ & 28 \\
\hline$e+\mathrm{Ar} \rightarrow \mathrm{Ar}^{+}+e+e$ & $\mathrm{~b}$ & 29 \\
\hline$e+\mathrm{Ar}^{*} \rightarrow \mathrm{Ar}^{+}+e+e$ & $\mathrm{~b}$ & 30 \\
\hline$e+\mathrm{NF}_{x} \rightarrow \mathrm{NF}_{x}+e$ & $\mathrm{~b}, \mathrm{e}$ & 31 \\
\hline$e+\mathrm{NF}_{x} \rightarrow \mathrm{NF}_{x}(v)+e$ & $\mathrm{~b}, \mathrm{e}, \mathrm{f}$ & 32 \\
\hline$e+\mathrm{NF}_{3} \rightarrow \mathrm{NF}_{2}+\mathrm{F}+e$ & $\mathrm{~b}$ & 31 \\
\hline$e+\mathrm{NF}_{3} \rightarrow \mathrm{NF}+\mathrm{F}+\mathrm{F}+e$ & $\mathrm{~b}$ & 31 \\
\hline$e+\mathrm{NF}_{3} \rightarrow \mathrm{NF}_{2}+\mathrm{F}^{-}$ & $\mathrm{b}$ & 33 \\
\hline$e+\mathrm{NF}_{3} \rightarrow \mathrm{NF}_{3}^{+}+e+e$ & $\mathrm{~b}$ & 34 \\
\hline$e+\mathrm{NF}_{3} \rightarrow \mathrm{NF}_{2}^{+}+\mathrm{F}+e+e$ & $\mathrm{~b}$ & 34 \\
\hline$e+\mathrm{NF}_{3} \rightarrow \mathrm{NF}^{+}+\mathrm{F}+\mathrm{F}+e+e$ & $\mathrm{~b}$ & 34 \\
\hline$e+\mathrm{NF}_{2} \rightarrow \mathrm{NF}+\mathrm{F}+e$ & b & 32 \\
\hline$e+\mathrm{NF}_{2} \rightarrow \mathrm{N}+\mathrm{F}+\mathrm{F}+e$ & $\mathrm{~b}$ & 32 \\
\hline$e+\mathrm{NF}_{2} \rightarrow \mathrm{NF}_{2}^{+}+e+e$ & $\mathrm{~b}$ & 34 \\
\hline$e+\mathrm{NF}_{2} \rightarrow \mathrm{NF}+\mathrm{F}^{-}$ & $\mathrm{b}$ & $32,33,{ }^{g}$ \\
\hline$e+\mathrm{NF} \rightarrow \mathrm{N}+\mathrm{F}+e$ & $\mathrm{~b}$ & 32 \\
\hline$e+\mathrm{NF} \rightarrow \mathrm{NF}^{+}+e+e$ & $\mathrm{~b}$ & 34 \\
\hline$e+\mathrm{NF}_{3}^{+} \rightarrow \mathrm{NF}_{2}+\mathrm{F}$ & $1 \times 10^{-7} T_{e}^{-0.5}$ & 35 \\
\hline$e+\mathrm{NF}_{2}^{+} \rightarrow \mathrm{NF}+\mathrm{F}$ & $1 \times 10^{-7} T_{e}^{-0.5}$ & 35 \\
\hline$e+\mathrm{NF}^{+} \rightarrow \mathrm{N}+\mathrm{F}$ & $1 \times 10^{-7} T_{e}^{-0.5}$ & 35 \\
\hline$e+\mathrm{F}_{2} \rightarrow \mathrm{F}_{2}+e$ & $\mathrm{~b}$ & 36 \\
\hline$e+\mathrm{F}_{2} \rightarrow \mathrm{F}_{2}(v)+e$ & $\mathrm{~b}, \mathrm{f}$ & 36 \\
\hline$e+\mathrm{F}_{2} \rightarrow \mathrm{F}^{-}+\mathrm{F}$ & $\mathrm{b}$ & 36 \\
\hline$e+\mathrm{F}_{2} \rightarrow \mathrm{F}+\mathrm{F}+e$ & b & 36 \\
\hline$e+\mathrm{F}_{2} \rightarrow \mathrm{F}_{2}^{+}+e+e$ & 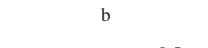 & 36 \\
\hline$e+\mathrm{F}_{2}^{+} \rightarrow \mathrm{F}+\mathrm{F}$ & $1 \times 10^{-7} T_{e}^{-0.5}$ & 36 \\
\hline$e+\mathrm{F} \rightarrow \mathrm{F}+e$ & $\mathrm{~b}$ & 37 \\
\hline$e+\mathrm{F} \rightarrow \mathrm{F}^{*}+e$ & $\mathrm{~b}, \mathrm{f}$ & 37 \\
\hline$e+\mathrm{F} \rightarrow \mathrm{F}^{+}+e+e$ & $\mathrm{~b}$ & 38 \\
\hline$e+\mathrm{N}_{2} \rightarrow \mathrm{N}_{2}+e$ & $\mathrm{~b}$ & 39 \\
\hline$e+\mathrm{N}_{2} \rightarrow \mathrm{N}_{2}(v)+e$ & $\mathrm{~b}, \mathrm{f}$ & 39 \\
\hline$e+\mathrm{N}_{2} \leftrightarrow \mathrm{N}_{2}^{*}+e$ & $\mathrm{~b}, \mathrm{c}, \mathrm{h}$ & $40-42$ \\
\hline$e+\mathrm{N}_{2} \rightarrow \mathrm{N}+\mathrm{N}+e$ & $\mathrm{~b}$ & 39 \\
\hline$e+\mathrm{N}_{2} \rightarrow \mathrm{N}_{2}^{+}+e+e$ & $\mathrm{~b}$ & 29 \\
\hline$e+\mathrm{N}_{2}^{*} \rightarrow \mathrm{N}_{2}^{+}+e+e$ & 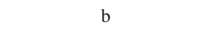 & 43 \\
\hline$e+\mathrm{N}_{2}^{+} \rightarrow \mathrm{N}^{*}+\mathrm{N}$ & $1 \times 10^{-7} T_{e}^{-0.5}$ & 44 \\
\hline$e+\mathrm{N} \rightarrow \mathrm{N}+e$ & b & 45 \\
\hline$e+\mathrm{N} \leftrightarrow \mathrm{N}^{*}+e$ & $\mathrm{~b}, \mathrm{c}, \mathrm{i}$ & 46 \\
\hline$e+\mathrm{N} \rightarrow \mathrm{N}^{+}+e+e$ & $\mathrm{~b}$ & 47 \\
\hline$e+\mathrm{N}^{*} \rightarrow \mathrm{N}^{+}+e+e$ & $\mathrm{~b}$ & 43 \\
\hline $\mathrm{Ar}^{*}+\mathrm{Ar}^{*} \rightarrow \mathrm{Ar}^{+}+\mathrm{Ar}+e$ & $5 \times 10^{-10}$ & 48 \\
\hline $\mathrm{Ar}^{*}+\mathrm{N}^{*} \rightarrow \mathrm{N}^{+}+\mathrm{Ar}+e$ & $5 \times 10^{-10}$ & $\mathrm{j}$ \\
\hline $\mathrm{Ar}^{*}+\mathrm{N} \rightarrow \mathrm{N}^{*}+\mathrm{Ar}$ & $1 \times 10^{-12}$ & $\mathrm{j}$ \\
\hline $\mathrm{Ar}^{*}+\mathrm{N}_{2}^{*} \rightarrow \mathrm{N}_{2}^{+}+\mathrm{Ar}+e$ & $5 \times 10^{-10}$ & $\mathrm{j}$ \\
\hline $\mathrm{Ar}^{*}+\mathrm{N}_{2} \rightarrow \mathrm{N}_{2}+\mathrm{Ar}$ & $3.6 \times 10^{-11}$ & 49 \\
\hline $\mathrm{Ar}^{*}+\mathrm{NF}_{3} \rightarrow \mathrm{NF}_{2}+\mathrm{F}+\mathrm{Ar}$ & $1 \times 10^{-10}$ & 50 \\
\hline $\mathrm{Ar}^{+}+\mathrm{N}_{2} \rightarrow \mathrm{N}_{2}^{+}+\mathrm{Ar}$ & $1 \times 10^{-11}$ & 51 \\
\hline $\mathrm{Ar}^{+}+\mathrm{N}_{2}^{*} \rightarrow \mathrm{N}_{2}^{+}+\mathrm{Ar}$ & $1 \times 10^{-11}$ & 51 \\
\hline $\mathrm{Ar}^{+}+\mathrm{N} \rightarrow \mathrm{N}^{+}+\mathrm{Ar}$ & $1 \times 10^{-11}$ & $\mathrm{j}$ \\
\hline
\end{tabular}

TABLE I. (Continued.)

\begin{tabular}{|c|c|c|}
\hline \multicolumn{3}{|l|}{ Species } \\
\hline $\mathrm{Ar}^{+}+\mathrm{N}^{*} \rightarrow \mathrm{N}^{+}+\mathrm{Ar}$ & $1 \times 10^{-11}$ & $\mathrm{j}$ \\
\hline $\mathrm{Ar}^{+}+\mathrm{NF}_{3} \rightarrow \mathrm{NF}_{2}^{+}+\mathrm{F}+\mathrm{Ar}$ & $1 \times 10^{-11}$ & 52 \\
\hline $\mathrm{Ar}^{+}+\mathrm{NF}_{2} \rightarrow \mathrm{NF}_{2}^{+}+\mathrm{Ar}$ & $1 \times 10^{-11}$ & $\mathrm{j}$ \\
\hline $\mathrm{Ar}^{+}+\mathrm{NF} \rightarrow \mathrm{NF}^{+}+\mathrm{Ar}$ & $5 \times 10^{-12}$ & $\mathrm{j}$ \\
\hline $\mathrm{F}^{+}+\mathrm{NF}_{3} \rightarrow \mathrm{NF}_{2}^{+}+\mathrm{F}+\mathrm{F}$ & $1 \times 10^{-11}$ & j \\
\hline $\mathrm{F}^{+}+\mathrm{NF}_{2} \rightarrow \mathrm{NF}_{2}^{+}+\mathrm{F}$ & $1 \times 10^{-11}$ & $53,{ }^{\mathrm{k}}$ \\
\hline $\mathrm{F}^{+}+\mathrm{NF} \rightarrow \mathrm{NF}^{+}+\mathrm{F}$ & $1 \times 10^{-11}$ & j \\
\hline $\mathrm{F}^{+}+\mathrm{N}_{2} \rightarrow \mathrm{N}_{2}^{+}+\mathrm{F}$ & $1 \times 10^{-11}$ & 54 \\
\hline $\mathrm{F}^{+}+\mathrm{N} \rightarrow \mathrm{N}^{+}+\mathrm{F}$ & $1 \times 10^{-11}$ & $53,^{l}$ \\
\hline $\mathrm{F}_{2}^{+}+\mathrm{NF}_{3} \rightarrow \mathrm{NF}_{2}^{+}+\mathrm{F}+\mathrm{F}_{2}$ & $1 \times 10^{-11}$ & $\mathrm{j}$ \\
\hline $\mathrm{F}_{2}^{+}+\mathrm{NF}_{2} \rightarrow \mathrm{NF}_{2}^{+}+\mathrm{F}_{2}$ & $1 \times 10^{-11}$ & j \\
\hline $\mathrm{F}_{2}^{+}+\mathrm{NF} \rightarrow \mathrm{NF}^{+}+\mathrm{F}_{2}$ & $1 \times 10^{-11}$ & j \\
\hline $\mathrm{F}_{2}^{+}+\mathrm{N}_{2} \rightarrow \mathrm{N}_{2}^{+}+\mathrm{F}_{2}$ & $5 \times 10^{-12}$ & $\mathrm{j}$ \\
\hline $\mathrm{F}_{2}^{+}+\mathrm{N} \rightarrow \mathrm{N}^{+}+\mathrm{F}_{2}$ & $1 \times 10^{-11}$ & $\mathrm{j}$ \\
\hline $\mathrm{N}^{+}+\mathrm{NF}_{3} \rightarrow \mathrm{NF}_{3}^{+}+\mathrm{N}$ & $1 \times 10^{-11}$ & $55,{ }^{\mathrm{m}}$ \\
\hline $\mathrm{N}^{+}+\mathrm{NF}_{2} \rightarrow \mathrm{NF}_{2}^{+}+\mathrm{N}$ & $1 \times 10^{-11}$ & $55,^{\mathrm{g}}$ \\
\hline $\mathrm{N}_{2}^{+}+\mathrm{N} \rightarrow \mathrm{N}^{+}+\mathrm{N}_{2}$ & $5 \times 10^{-12}$ & 56 \\
\hline $\mathrm{N}_{2}^{+}+\mathrm{N}^{*} \rightarrow \mathrm{N}^{+}+\mathrm{N}_{2}$ & $1 \times 10^{-10}$ & $56,^{\mathrm{n}}$ \\
\hline $\mathrm{N}_{2}^{+}+\mathrm{NF}_{3} \rightarrow \mathrm{NF}_{2}^{+}+\mathrm{F}+\mathrm{N}_{2}$ & $1 \times 10^{-11}$ & 55 \\
\hline $\mathrm{N}_{2}^{+}+\mathrm{NF}_{2} \rightarrow \mathrm{NF}_{2}^{+}+\mathrm{N}_{2}$ & $1 \times 10^{-11}$ & 55 \\
\hline $\mathrm{NF}_{2}^{+}+\mathrm{NF}_{3} \rightarrow \mathrm{NF}_{3}^{+}+\mathrm{NF}_{2}$ & $1 \times 10^{-9}$ & $57,{ }^{\circ}$ \\
\hline $\mathrm{NF}^{+}+\mathrm{NF}_{3} \rightarrow \mathrm{NF}_{3}^{+}+\mathrm{NF}$ & $1 \times 10^{-11}$ & 58 \\
\hline $\mathrm{NF}^{+}+\mathrm{NF}_{2} \rightarrow \mathrm{NF}_{2}^{+}+\mathrm{NF}$ & $1 \times 10^{-11}$ & 58 \\
\hline $\mathrm{F}^{-}+\mathrm{Ar}^{+} \rightarrow \mathrm{F}+\mathrm{Ar}$ & $1 \times 10^{-7}$ & 59 \\
\hline $\mathrm{F}^{-}+\mathrm{F}_{2}^{+} \rightarrow \mathrm{F}+\mathrm{F}_{2}$ & $1 \times 10^{-7}$ & 53 \\
\hline $\mathrm{F}^{-}+\mathrm{F}^{+} \rightarrow \mathrm{F}+\mathrm{F}$ & $1 \times 10^{-7}$ & 53 \\
\hline $\mathrm{F}^{-}+\mathrm{NF}_{3}^{+} \rightarrow \mathrm{F}+\mathrm{NF}_{3}$ & $1 \times 10^{-7}$ & 53 \\
\hline $\mathrm{F}^{-}+\mathrm{NF}_{2}^{+} \rightarrow \mathrm{F}+\mathrm{NF}_{2}$ & $1 \times 10^{-7}$ & 53 \\
\hline $\mathrm{F}^{-}+\mathrm{NF}^{+} \rightarrow \mathrm{F}+\mathrm{NF}$ & $1 \times 10^{-7}$ & 53 \\
\hline $\mathrm{F}^{-}+\mathrm{N}_{2}^{+} \rightarrow \mathrm{F}+\mathrm{N}_{2}$ & $1 \times 10^{-7}$ & 53 \\
\hline $\mathrm{F}^{-}+\mathrm{N}^{+} \rightarrow \mathrm{F}+\mathrm{N}$ & $1 \times 10^{-7}$ & 53 \\
\hline $\mathrm{F}+\mathrm{F}+M \rightarrow \mathrm{F}_{2}+M$ & $6.77 \times 10^{-28} \mathrm{~cm}^{6} \mathrm{~s}^{-1}$ & 60 \\
\hline $\mathrm{NF}_{2}+\mathrm{F}+M \rightarrow \mathrm{NF}_{3}+M$ & $5 \times 10^{-31} \mathrm{~cm}^{6} \mathrm{~s}^{-1}$ & 61 \\
\hline $\mathrm{NF}+\mathrm{NF} \rightarrow \mathrm{N}_{2}+\mathrm{F}+\mathrm{F}$ & $6.88 \times 10^{-11} e^{-1251 / T}$ & 62 \\
\hline $\mathrm{NF}+\mathrm{NF} \rightarrow \mathrm{F}_{2}+\mathrm{N}_{2}$ & $4 \times 10^{-12}$ & 62,63 \\
\hline $\mathrm{NF}_{2}+\mathrm{N} \rightarrow \mathrm{NF}+\mathrm{NF}$ & $3 \times 10^{-12}$ & 64 \\
\hline $\mathrm{NF}_{2}+\mathrm{N} \rightarrow \mathrm{F}+\mathrm{F}+\mathrm{N}_{2}$ & $1.4 \times 10^{-11} e^{-95 / T}$ & 65 \\
\hline $\mathrm{N}_{2}^{*}+\mathrm{NF}_{3} \rightarrow \mathrm{NF}_{2}+\mathrm{F}+\mathrm{N}_{2}$ & $1 \times 10^{-11}$ & $66,{ }^{\mathrm{m}}$ \\
\hline $\mathrm{N}_{2}^{*}+\mathrm{N}_{2} \rightarrow \mathrm{N}_{2}+\mathrm{N}_{2}$ & $1.9 \times 10^{-13}$ & 67 \\
\hline $\mathrm{N}_{2}^{*}+\mathrm{N} \rightarrow \mathrm{N}_{2}+\mathrm{N}$ & $1 \times 10^{-13}$ & $\mathrm{j}$ \\
\hline $\mathrm{N}_{2}^{*}+\mathrm{N}^{*} \rightarrow \mathrm{N}_{2}+\mathrm{N}$ & $1 \times 10^{-13}$ & j \\
\hline $\mathrm{N}^{*}+\mathrm{N}_{2} \rightarrow \mathrm{N}+\mathrm{N}_{2}$ & $2 \times 10^{-14}$ & 68 \\
\hline $\mathrm{N}^{*}+\mathrm{N}+M \rightarrow \mathrm{N}_{2}^{*}+M$ & $2 \times 10^{-32} \mathrm{~cm}^{6} \mathrm{~s}^{-1}$ & $69,{ }^{\mathrm{n}}$ \\
\hline $\mathrm{N}+\mathrm{N}+M \rightarrow \mathrm{N}_{2}^{*}+M$ & $1 \times 10^{-32} \mathrm{~cm}^{6} \mathrm{~s}^{-1}$ & 69 \\
\hline $\mathrm{N}+\mathrm{N}+M \rightarrow \mathrm{N}_{2}+M$ & $1 \times 10^{-32} \mathrm{~cm}^{6} \mathrm{~s}^{-1}$ & 69 \\
\hline $\mathrm{N}_{2}^{*}+\mathrm{N}_{2}^{*} \rightarrow \mathrm{N}_{2}+\mathrm{N}_{2}^{*}$ & $1.36 \times 10^{-9}$ & 67,70 \\
\hline
\end{tabular}

${ }^{\mathrm{a}}$ Rate coefficients have units of $\mathrm{cm}^{3} \mathrm{~s}^{-1}$ unless noted otherwise.

b The rate coefficient was obtained by solving Boltzmann's equation for the electron energy distribution. Cross sections for the process are from the indicated reference.

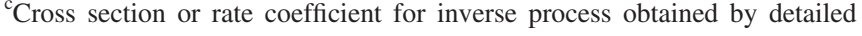
balance.

${ }^{\mathrm{d}} \mathrm{Ar}^{*}$ nominally represents $\operatorname{Ar}(4 s)$ and includes excitation to that and higher lying states.

${ }^{\mathrm{e}}$ Cross section for $\mathrm{NF}_{3}$. Analogous cross sections used for $\mathrm{NF}_{x}(x<3)$.

${ }^{\mathrm{f}}$ Inelastic loss is included in the calculation of electron energy distributions; however, excited state is not included in the model.

${ }^{\mathrm{g}}$ Estimated by analogy to $\mathrm{NF}_{3}$.

${ }^{\mathrm{h}} \mathrm{N}_{2}{ }^{*}$ nominally represents $\mathrm{N}_{2}(A)$ and includes excitation to that and higher lying states.

${ }^{\mathrm{i}} \mathrm{N}^{*}$ nominally represents $\mathrm{N}\left({ }^{2} D\right)$ and includes excitation to that and higher lying states. 
${ }^{\mathrm{j}}$ Estimated.

${ }^{\mathrm{k}}$ Estimated by analogy to $\mathrm{CF}_{2}$.

${ }^{\mathrm{l}}$ Estimated by analogy to $\mathrm{C}$.

${ }^{\mathrm{m}}$ Estimated by analogy to $\mathrm{NH}_{3}$.

${ }^{\mathrm{n}}$ Estimated by analogy to $\mathrm{N}$.

${ }^{\circ}$ Estimated by analogy to $\mathrm{PF}_{3}$.

electron transport, such as elastic collisions, and vibrational and electronic excitations, are included in the EETM. Only those excited states which were judged to be significant to the plasma chemistry reaction mechanism were tracked in the FKM and appear in the reaction mechanism.

To lessen the complexity of the reaction mechanism, lumped effective excited states were used. Excited states of Ar were lumped into $\mathrm{Ar}^{*}$, which is effectively $\operatorname{Ar}(4 s)$. Excitation to the electronic states of $\mathrm{N}_{2}$ were lumped into $\mathrm{N}_{2}{ }^{*}$ which is effectively $\mathrm{N}\left(A^{3} \Sigma_{u}^{+}\right)$. Similarly, the higher excited states of $\mathrm{N}\left[\mathrm{N}\left({ }^{2} \mathrm{D}\right)\right.$ and $\left.\mathrm{N}\left({ }^{4} \mathrm{P}\right)\right]$ are lumped together and denoted as $\mathrm{N}^{*}$.

Many of the rate coefficients involving fragments of $\mathrm{NF}_{3}$ (i.e., $\mathrm{NF}_{2}$ and $\mathrm{NF}$ ) for electron impact and neutral heavy particle reactions were estimated. Although an exhaustive sensitivity analysis has not been performed, the systematic trends discussed here are not sensitive functions of the values of these coefficients.

\section{EFFECT OF PULSED-DC BIAS ON IEADS AND PLASMA CHARACTERISTICS}

The cylindrically symmetric reactor used in this study is schematically shown in Fig. 1. Inductive power is supplied through a three-turn coil, $42 \mathrm{~cm}$ in diameter. The coils are behind a $1 \mathrm{~cm}$ thick ring of dielectric having, in the model, the electrical properties of alumina. Process gases, $\mathrm{Ar} / \mathrm{NF}_{3}$ in this case (a surrogate for $\mathrm{Ar} / \mathrm{BF}_{3}$ that would normally be used for ion implantation processes), enter the chamber from the nozzle at the top and center of the reactor, and are exhausted from an annular pump port. The top reactor surface is metal as it intercepts significant secondary electron current from the sheath accelerated electrons. The $30 \mathrm{~cm}$ diameter wafer is on a substrate which is biased by a pulsed dc power supply. The wafer is about $14 \mathrm{~cm}$ below the nozzle. A 10 mTorr, $\mathrm{Ar} / \mathrm{NF}_{3}=80 / 20$ gas mixture at a flow rate of $100 \mathrm{sccm}$ ( $\mathrm{sccm}$ denotes cubic centimeters per minute at STP) was used for the base case. The coil delivered $500 \mathrm{~W}$ at $10 \mathrm{MHz}$ excitation frequency.

The pulsed dc bias voltage waveform used for the base case is shown in Fig. 2. The excitation waveform was applied at $8.7 \mathrm{kHz}$ and consisted of sequences of $45 \mu \mathrm{s}$ long negative voltage pulses followed by a pulse-off time $\left(\Delta t_{i}\right)$ of $70 \mu \mathrm{s}$. The pulse has a linear rise of voltage to a constant bias and a linear fall to zero. The rise time and fall times, $\Delta t_{r}$, for the base case are $5 \mu \mathrm{s}$. As explained below, the rate of voltage rise and voltage pulse length are critical in determining plasma characteristics and are important to the shape of the IEADs.

A typical computational strategy is as follows. Initial conditions (e.g., plasma density and dissociation fraction) are estimated and the model executed with only ICP power for $60 \mu$ s to achieve a quasisteady state in plasma characteristics. The effective integration time is actually 10-100 times
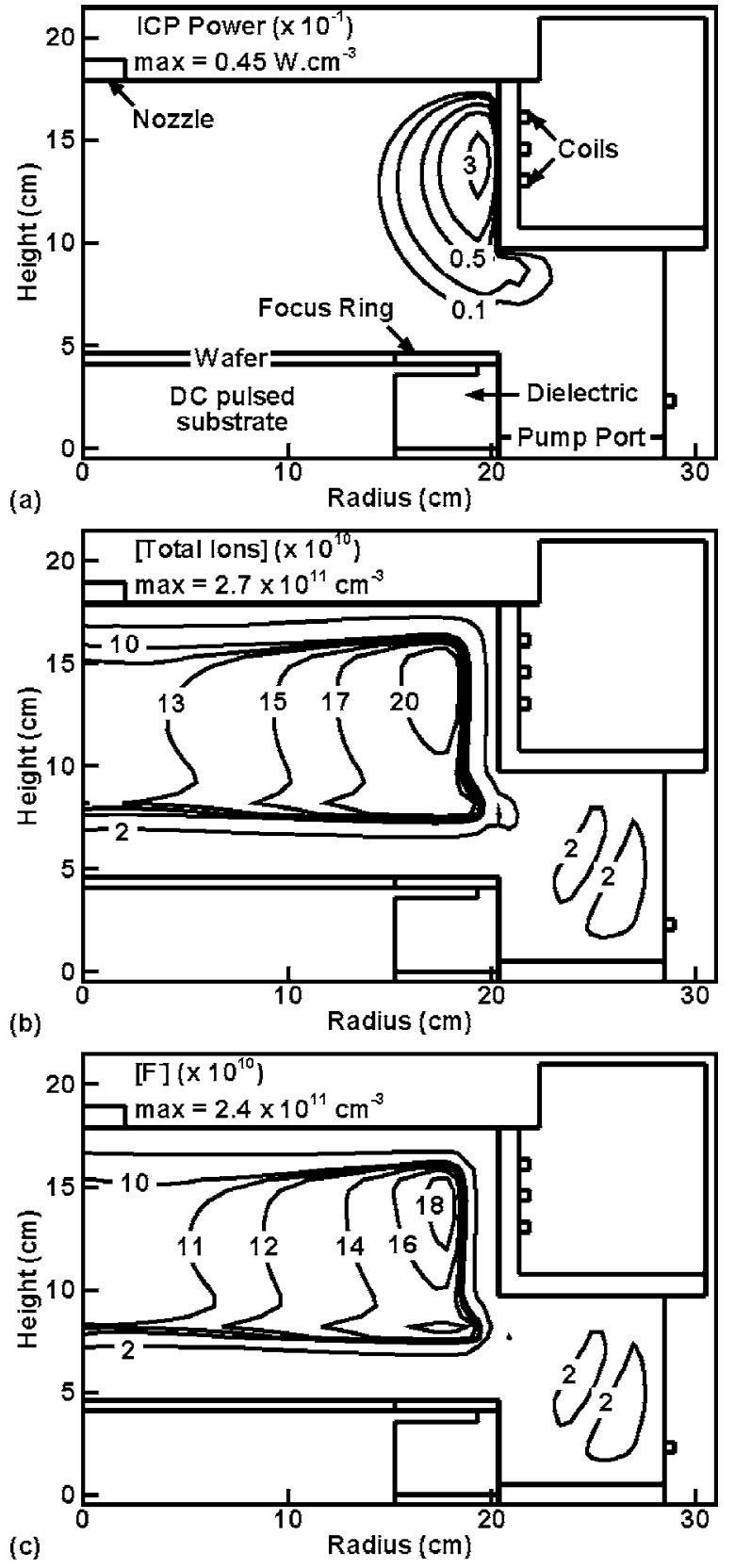

FIG. 1. Plasma properties for the base case $\left(\mathrm{Ar} / \mathrm{NF}_{3}=80 / 20,500 \mathrm{~W}\right.$ ICP power, $10 \mathrm{mTorr}, 100 \mathrm{sccm}$ ) and $-1000 \mathrm{~V}$ substrate bias. (a) Power, (b) total ion density, and (c) $\mathrm{F}^{-}$density. Note the depletion of ions in the sheath above the substrate and the islands of ions in the periphery of the reactor.

longer than $60 \mu \mathrm{s}$ as acceleration techniques are used to speed the convergence of plasma properties. Four voltage pulses (and their interpulse periods) are then applied using direct time integration in the model without applying acceleration techniques. The plasma properties we discuss below are those for the fourth pulse at different times during the pulse. We confirmed that the plasma properties do not significantly change with application of additional pulses as the interpulse period is usually long enough to lose memory of the prior pulse. The PCMCM is executed approximately every $1 \mu$ s to obtain the time history of the IEADs, which is then time integrated to obtain a pulse averaged IEAD.

The inductively coupled power deposition, total positive ion density, and $\mathrm{F}^{-}$density are shown in Fig. 1 for the base 


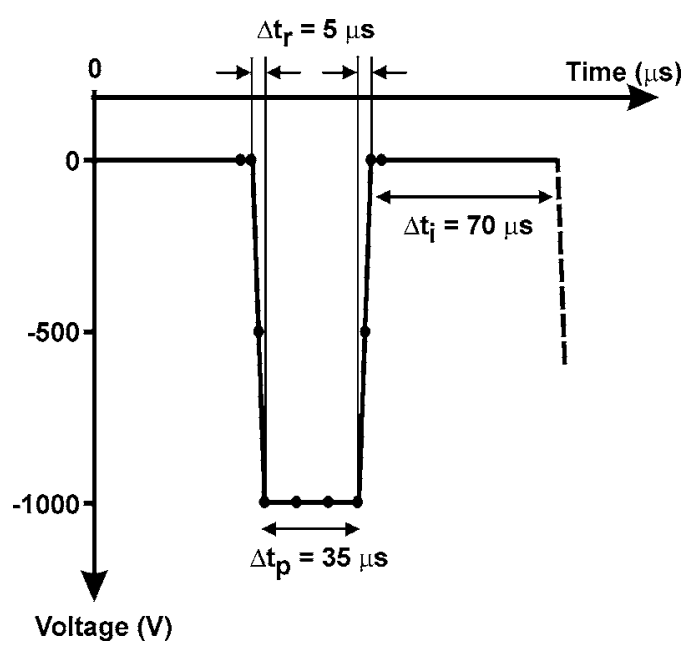

FIG. 2. Schematic of the pulsed voltage waveform. The base case voltage pulse is $45 \mu$ s long with a pulse-off time of $70 \mu$ s between the pulses. Four such voltage pulses are applied in the model to reach a quasi-steady-state.

case, when the bias voltage is midway through the fourth pulse and has an amplitude of $-1000 \mathrm{~V}$. Similarly the densities of $\mathrm{Ar}^{+}, \mathrm{NF}_{3}{ }^{+}$, and $\mathrm{NF}_{2}{ }^{+}$are shown in Fig. 3. The high electron thermal conductivity produces a fairly uniform electron temperature $(4-5 \mathrm{eV})$ in spite of the localized power deposition in the vicinity of the coils. The ion density is maximum at $2.7 \times 10^{11} \mathrm{~cm}^{-3}$ near the peak in power deposition, with $\mathrm{Ar}^{+}$being the major ion and $\mathrm{NF}_{3}{ }^{+}$and other dissociation fragments being an order of magnitude lower in densities. The off axis maximum in ion density is a consequence of the low aspect ratio of the reactor ${ }^{72}$ and highly attaching nature of the gas mixture which rapidly consumes electrons. Although the total ion density peaks off axis, the density of $\mathrm{NF}_{3}^{+}$peaks below the nozzle where its neutral density is largest. As discussed below, the large bias voltage creates a sheath that can be many centimeters thick and depletes both electrons and ions near the substrate. The islands of ions in the periphery of the reactor will be discussed later.

Time-averaged radical and ion fluxes to the wafer are shown in Fig. 4 for the base case conditions. The radicals having the largest fluxes to the substrate are, on axis, $\mathrm{F}$ $\left(5.9 \times 10^{17} \mathrm{~cm}^{-2} \mathrm{~s}^{-1}\right), \quad \mathrm{NF}_{2}\left(2.6 \times 10^{17} \mathrm{~cm}^{-2} \mathrm{~s}^{-1}\right)$, and $\mathrm{NF}$ $\left(0.9 \times 10^{17} \mathrm{~cm}^{-2} \mathrm{~s}^{-1}\right)$. Dissociation of the $\mathrm{NF}_{3}$ down to $\mathrm{N}$ atoms produces a flux that is an order of magnitude smaller. The largest flux of ions is due to $\mathrm{Ar}^{+}\left(2.9 \times 10^{15} \mathrm{~cm}^{-2} \mathrm{~s}^{-1}\right)$ due to its low rates of charge exchange to $\mathrm{NF}_{3}$ and its dissociation fragments. Fluxes of $\mathrm{NF}_{3}{ }^{+}$and $\mathrm{NF}_{2}{ }^{+}$are an order of magnitude lower. The ion fluxes are maximum on the outer radius near the coils where the total ion density and the power deposition also peak. This nonuniformity is not a characteristic of PPI but merely a consequence of this particular chamber design.

The electron and $\mathrm{NF}_{2}{ }^{+}$densities for a bias voltage of $-1000 \mathrm{~V}$ are shown in Fig. 5 at the end of the constant voltage portion of the bias for pressures of 5, 10, and 20 mTorr. The ICP power is held constant. The electron density, $n_{e}$, decreases from $7.5 \times 10^{10} \mathrm{~cm}^{-3}$ at 5 mTorr to 2.4 $\times 10^{10} \mathrm{~cm}^{-3}$ at $20 \mathrm{mTorr}$. This decrease results from the higher rate of electron attachment and the higher rate of
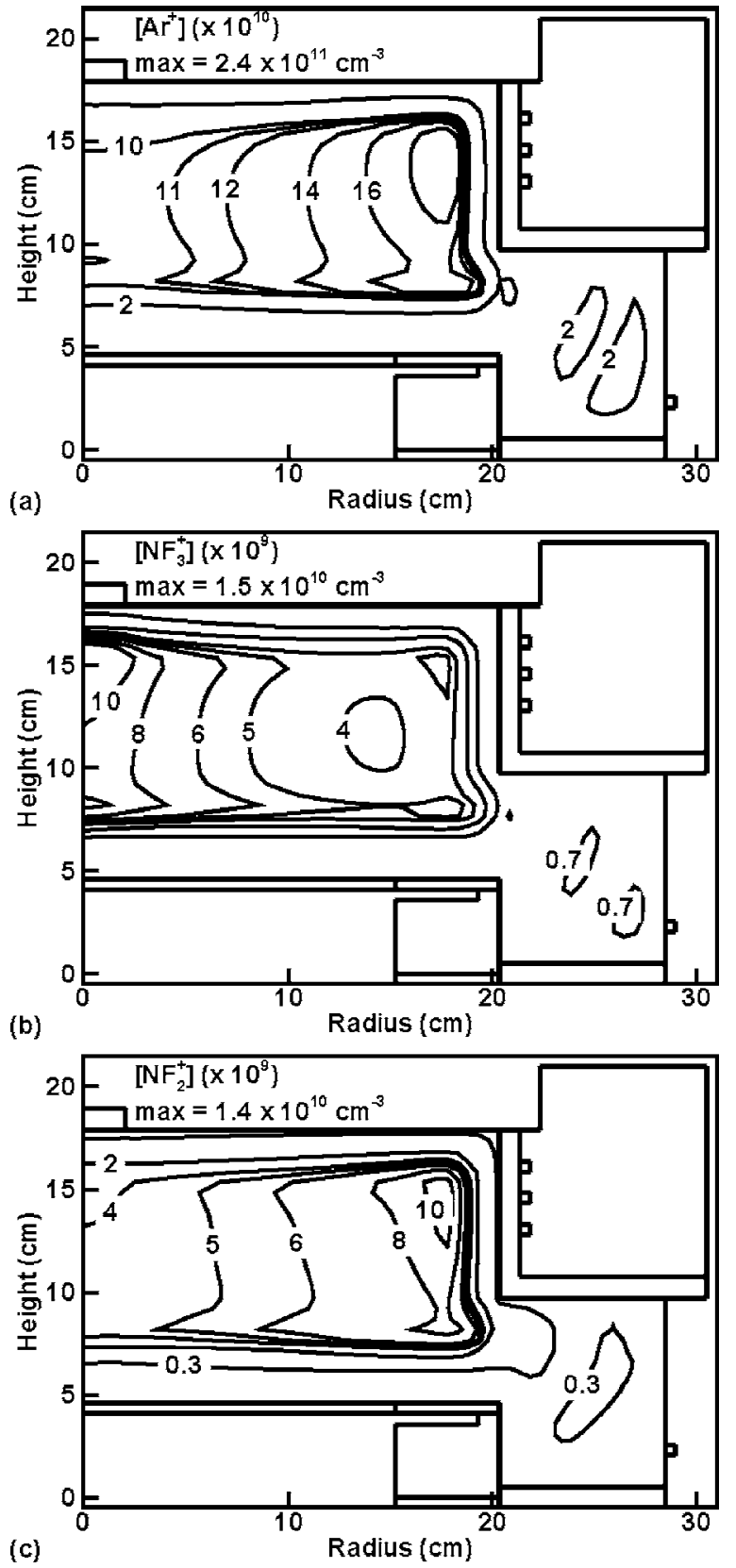

FIG. 3. Plasma properties for the base case $\left(\mathrm{Ar} / \mathrm{NF}_{3}=80 / 20,500 \mathrm{~W}\right.$ ICP power, $10 \mathrm{mTorr}, 100 \mathrm{sccm}$ ) and $-1000 \mathrm{~V}$ substrate bias. (a) $\mathrm{Ar}^{+}$, (b) $\mathrm{NF}_{3}^{+}$, and (c) $\mathrm{NF}_{2}{ }^{+}$densities. The densities are shown when the bias is midway through the fourth pulse.

power dissipation per electron at higher pressure. When holding the power constant, the electron density required to deliver the power decreases with increasing pressure. The $\mathrm{NF}_{2}{ }^{+}$density increases from $7.8 \times 10^{9}$ to $1.5 \times 10^{10} \mathrm{~cm}^{-3}$ with increasing pressure due to higher rates of charge exchange from $\mathrm{Ar}^{+}$. The longer mean free path for energy loss by electrons heated near the coils produces more uniform ionization sources at the lower pressure, and so a more uniform plasma is produced. To first order, the sheath thickness scales as $\lambda_{s} \sim V_{s} / n_{e}$, where $V_{s}$ is the sheath voltage and $n_{e}$ is the electron density at the sheath edge. Since $n_{e}$ decreases with increasing pressure, $\lambda_{s}$ increases. $\lambda_{s}$ is nearly uniform as a function of radius at 5 mTorr which reflects the uniformity 

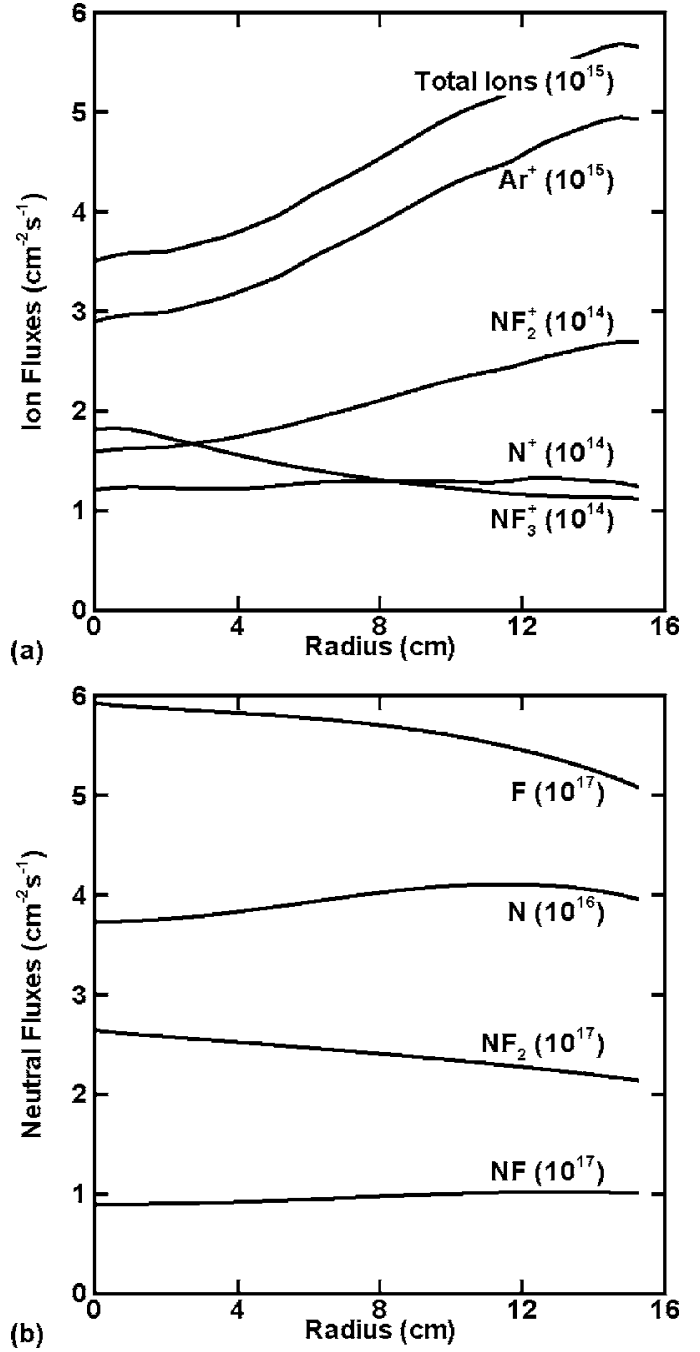

FIG. 4. Fluxes to the wafer as a function of radius for the base case conditions $\left(\mathrm{Ar} / \mathrm{NF}_{3}=80 / 20,500 \mathrm{~W}\right.$ ICP power, $\left.10 \mathrm{mTorr}, 100 \mathrm{sccm}\right)$. (a) Ion fluxes and (b) neutral fluxes. $\mathrm{NF}_{2}$ and $\mathrm{F}$ are the major neutral radical fluxes. $\mathrm{Ar}^{+}, \mathrm{NF}_{3}^{+}$, and $\mathrm{NF}_{2}^{+}$are the dominant ion fluxes.

in $n_{e}$. As $n_{e}$ is less uniform at higher pressure (larger at large radii) and so $\lambda_{s}$ is also less uniform, being smaller at large radii.

IEADs for all ions averaged over the voltage pulse and the interpulse periods are shown in Fig. 6(a) for base case conditions with bias voltages of -1000 to $-10000 \mathrm{~V}$. The ions that arrive at the sheath edge during the pulse-off period form the low energy, wide angular portion of the IEAD. The high energy and angularly narrow portion of the IEAD is produced during the voltage pulse. The peak value of the IEAD is located in energy a few tens of volts above the magnitude of the applied bias voltage. This is a consequence of the additional acceleration provided by the ambipolar potential.

The speed of the sheath into the plasma is as large as $10^{6} \mathrm{~cm} \mathrm{~s}^{-1}$ which is commensurate to or exceeds the thermal speed of the ions. The sheath is dominantly formed by expelling the more mobile electrons, exposing the less mobile ions and creating, at least initially, an ion-matrix sheath. ${ }^{73}$ The flux of the ions into the sheath during the voltage ramp-up period consists of ions which drift or diffuse into [e]

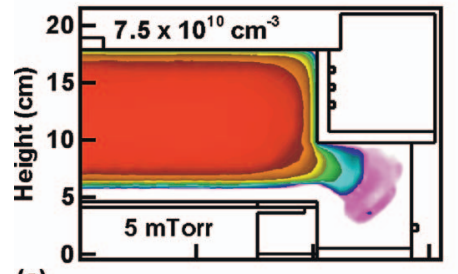

(a)
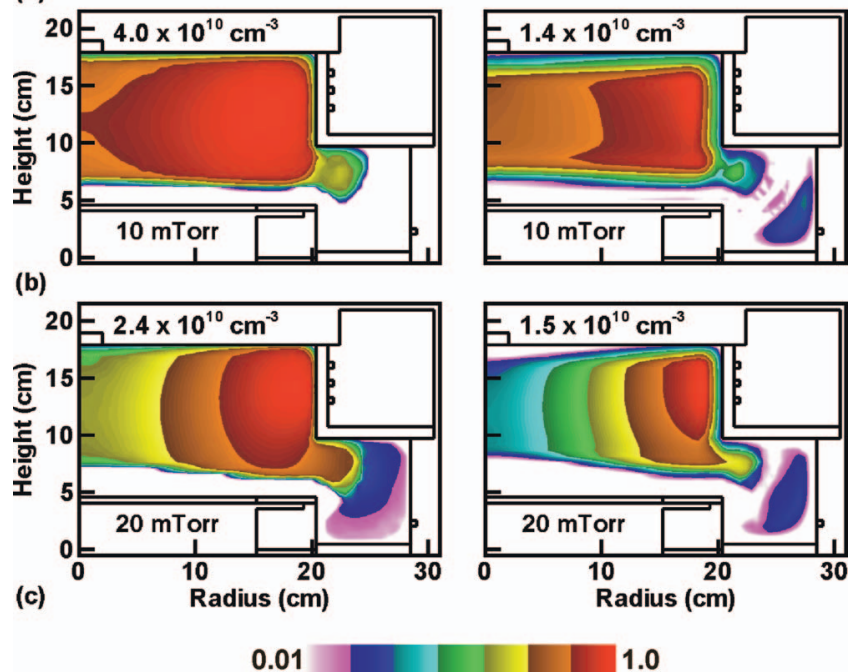

FIG. 5. (Color) Electron and $\mathrm{NF}_{2}^{+}$densities at base case conditions $\left(\mathrm{Ar} / \mathrm{NF}_{3}=80 / 20,500 \mathrm{~W}, 100 \mathrm{sccm}\right)$ and $-1000 \mathrm{~V}$ substrate bias as a function of pressure. (a) 5, (b) 10, and (c) 20 mTorr. The electron density decreases with increasing pressure and constant power due to a higher likelihood for attachment and large collisionality. These figures use a log scale plotted over 2 decades.

the sheath edge, and those ions which are enveloped by the growth of the sheath. During the constant voltage period of the pulse, the sheath grows only at the rate required to replenish ions that are extracted out of the sheath into the substrate.

The low energy tail of the IEAD results, in part, from ions that enter or are enveloped by the sheath during the ramp-up and ramp-down voltage pulses. These ions do not experience the full sheath voltage and so arrive at the substrate with lower energies. The tail of the IEAD is more prominent at higher bias voltages in large part because the sheath is thicker and there is significant ionization in the sheath resulting from secondary electrons emitted from the substrate. The ions produced in the sheath obtain in energy at most the difference between the plasma potential where they were produced and the bias voltage. The thicker sheath also produces a larger fraction of the ion flux which results from ions being captured by the sheath when electrons are expelled by expansion of the sheath (the ion-matrix component). The maximum energy of these ions is the sheath potential at the time at which the sheath captures them.

Ions experience only a nominal number of collisions (the mean free path for charge exchange is $\approx 1 \mathrm{~cm}$ ) during their transit through the sheath. As such, collisions contribute only in a minor way to the tail of the IEAD at low biases. At higher biases $(>5 \mathrm{kV})$ where the sheath thickness approaches the mean free path, collisions begin to populate the tail of the IEAD. 


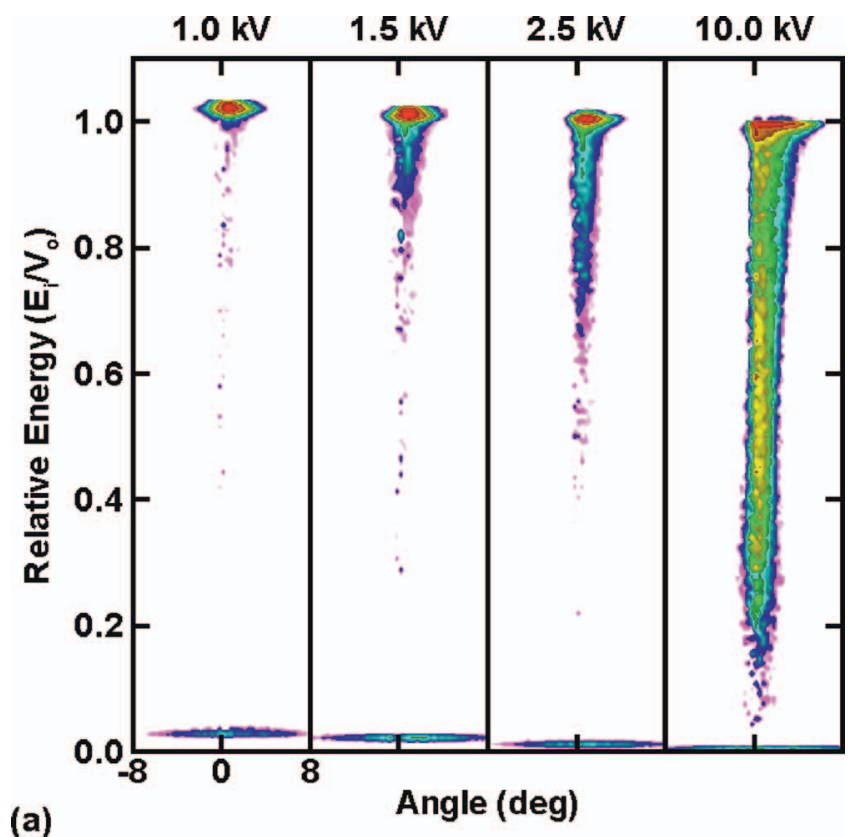

(a)

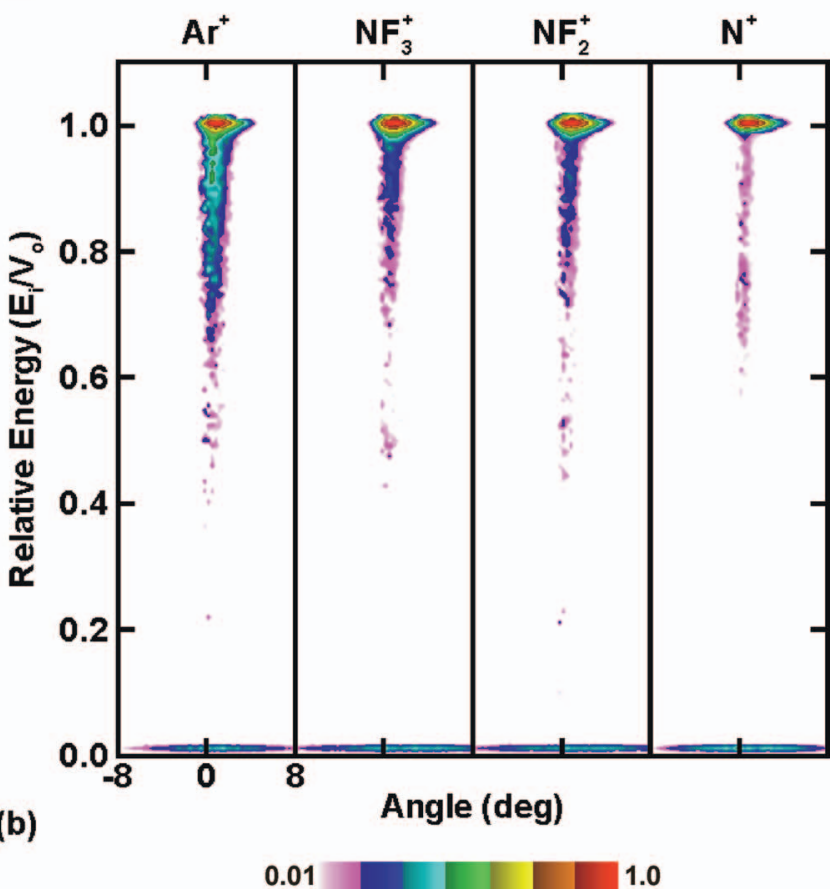

FIG. 6. (Color) IEADs averaged over the wafer for the base case conditions $\left(\mathrm{Ar} / \mathrm{NF}_{3}=80 / 20,500 \mathrm{~W}\right.$ ICP power, $\left.10 \mathrm{mTorr}, 100 \mathrm{sccm}\right)$ (a) IEADs for bias voltages of $1,2.5,5$, and $10 \mathrm{kV}$. The IEAD acquires an asymmetry as the bias voltage is increased. (b) IEADs for $\mathrm{Ar}^{+}, \mathrm{NF}_{3}{ }^{+}, \mathrm{NF}_{2}^{+}$and $\mathrm{N}^{+}$ions for a bias of $-2500 \mathrm{~V}$. IEADs for ions of the feedstock gases more prominent low energy tails due to ionization in the sheath. The energy peak of the IEAD is slightly higher for lighter ions along with a less prominent low energy tail. These figures use a log scale plotted over 2 decades.

The IEADs of individual ions display both mass and positional characteristics. The IEAD of the lightest ion, $\mathrm{N}^{+}$, is the most monoenergetic in spite of the fact that it will respond most quickly to changes in sheath potential which should broaden the energy spread of the IEAD. (This would be the case for a continuously applied, radio frequency sinusoidal bias of a few megahertz.) On the other hand, the heavier ions $\mathrm{Ar}^{+}$and $\mathrm{NF}_{3}{ }^{+}$, have the broadest energy spread, which is counterintuitive since these ions should be the slow- est to respond. These apparent discrepancies in the IEADs result from where the ions are formed. $\mathrm{Ar}^{+}$and $\mathrm{NF}_{3}{ }^{+}$, being parent ions of the feedstock gases, can be formed by single electron impact events in the sheaths by secondary electrons. As a result, the tails of the IEADs for $\mathrm{Ar}^{+}$and $\mathrm{NF}_{3}^{+}$are populated by ions formed in the sheath and which do not experience the full sheath potential. $\mathrm{N}^{+}$is formed dominantly by electron impact ionization of dissociation products, which occurs most often in the bulk plasma since many electron impact collisions are required. As such, the $\mathrm{N}^{+}$drifts or diffuses into the sheath from the bulk plasma and so attains the full sheath potential.

The tail of the IEAD can also be influenced by the duration of the ramp-up and ramp-down times $\left(\Delta t_{r}\right)$ of the voltage pulses. For example, the time-averaged IEADs for all ions are shown in Fig. 7(a) for a bias voltage of $-1000 \mathrm{~V}$ with $\Delta t_{r}$ of $1-15 \mu \mathrm{s}$. With increasing $\Delta t_{r}$, sheath expansion and retraction occupy a larger fraction of the duty cycle of the voltage pulse. As a result, a larger fraction of the ion flux entering the sheath does so while the sheath voltage is less than the maximum. The lower energy tail of the IEAD becomes particularly prominent for $\Delta t_{r}>10 \mu \mathrm{s}$. Nearly monoenergetic IEADs for all ions are obtained for $\Delta t_{r}<2 \mu \mathrm{s}$, as shown in Fig. 7(b).

The importance of the tail of the distribution at large bias voltages is demonstrated by the total ion energy distribution (IEDs), integrated over angle, shown in Fig. 8(a) for base case conditions with bias voltages of -1000 to $-10000 \mathrm{~V}$. The absolute maxima in the IEDs occurs at low energies, corresponding to times when the bias voltage is off (indicated by a horizontal line in the figure). Secondary maximum occurs at high energies corresponding to when the applied bias voltage is at its largest absolute value. The tail of the IED represents only a small fraction of the total IED at low bias energies. The low energy tail increases in importance, as the bias increases, as indicated by the decrease in the height of the high energy peak. More details of the tail of the IEADs are shown by the time-averaged distributions for $\mathrm{Ar}^{+}$, $\mathrm{NF}_{3}{ }^{+}, \mathrm{NF}_{2}{ }^{+}$, and $\mathrm{N}^{+}$ions in Fig. 8(b) for base case conditions and a bias voltage of $-10000 \mathrm{~V}$. To emphasize the tail, the IEADs are plotted as a 3 decade log scale.

Time-averaged IEADs for all ions are shown in Fig. 9(a) for a bias voltage of $-1000 \mathrm{~V}$ and for ICP powers of 250-1000 W. Time-averaged IEADs for $\mathrm{Ar}^{+}, \mathrm{NF}_{3}{ }^{+}, \mathrm{NF}_{2}{ }^{+}$, and $\mathrm{N}^{+}$are shown in Fig. 9(b) for base case conditions and an ICP power of $750 \mathrm{~W}$. The increase in ICP power produces an increase in ion density at the edge of the sheath and thinning of the sheath, as shown in Fig. 10. The total ion flux increases at higher ICP powers, as shown in Fig. 11, with there being a larger proportion of lighter ions (more dissociation at higher powers). As a result, as the ICP power increases the sheath becomes less collisional, the ion transit time decreases (in particular, for the lighter ions), and the amount of ionization by secondary electrons in the sheath decreases. These factors combine to reduce the population of ions in the low energy tail of the IEAD as the ICP power increases.

The electron density for a bias voltage of $-10000 \mathrm{~V}$ is shown in Fig. 12 for different times during the pulse between 


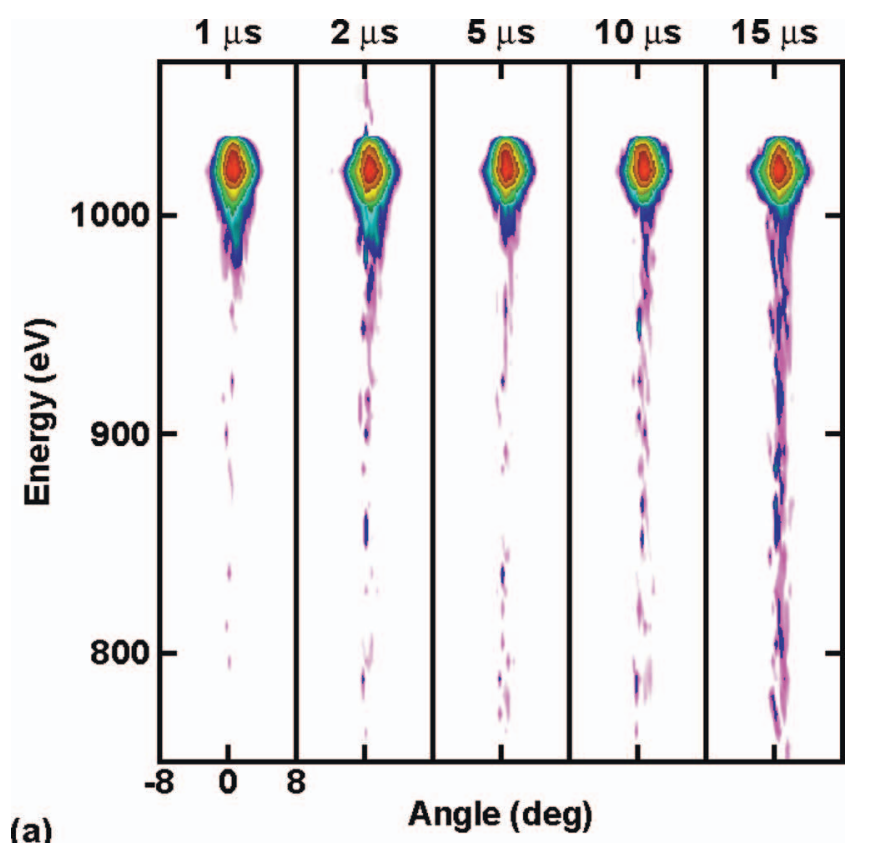

(a)

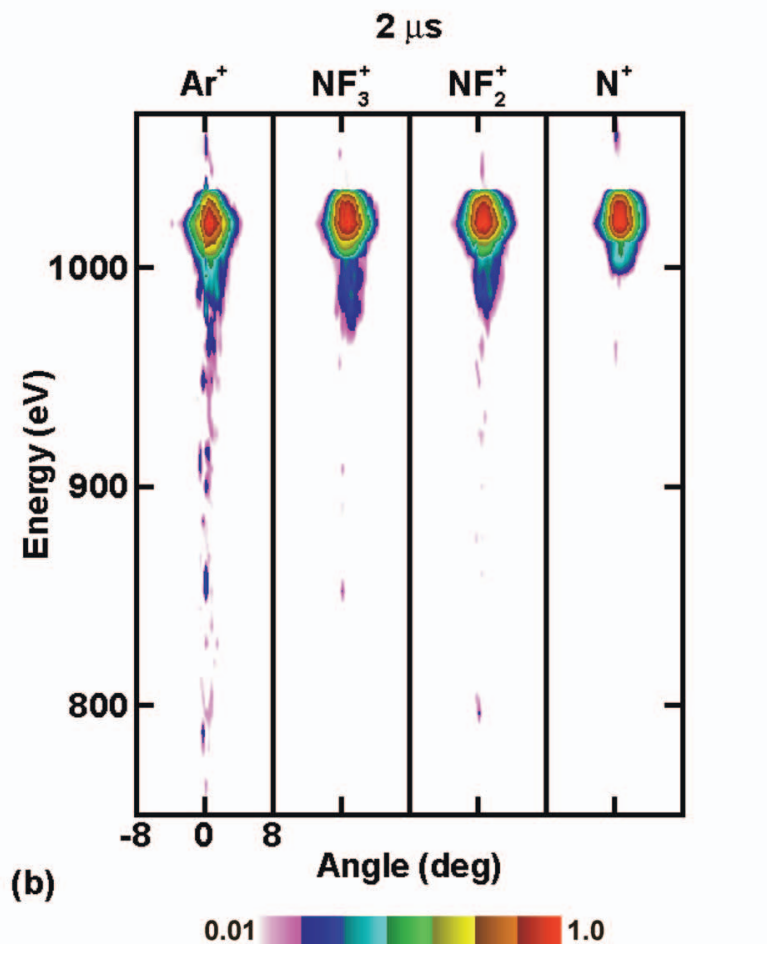

FIG. 7. (Color) IEADs averaged over the wafer for the base case conditions $\left(\mathrm{Ar} / \mathrm{NF}_{3}=80 / 20,500 \mathrm{~W}\right.$ ICP power, $\left.10 \mathrm{mTorr}, 100 \mathrm{sccm}\right)$. (a) Total ion energy and angular distributions for different lengths of the bias ramp-up period, $\Delta t_{r}$. The tail of the IEAD increases as the rate of increase of voltage decreases, as more ions enter the sheath during the ramp up and ramp down of voltage pulse. (b) IEADs for $\mathrm{Ar}^{+}, \mathrm{NF}_{3}{ }^{+}, \mathrm{NF}_{2}{ }^{+}$, and $\mathrm{N}^{+}$ions at base case conditions ( $-1000 \mathrm{~V}$ substrate bias) and $\Delta t_{r}=2 \mu \mathrm{s}$. These figures use a log scale plotted over 2 decades.

prior to the application of bias (frame 1) through the end of the voltage pulse (frame 10). The maximum electron density is $6.3 \times 10^{10} \mathrm{~cm}^{-3}$. Note the thickening of the sheath as the applied voltage becomes more negative, and the collapse and thinning of the sheath as the voltage is removed. The sheath initially has a nearly uniform thickness across the substrate as the electron and ion densities near the wafer are fairly uniform. As the sheath thickens, the edge of the sheath pen-

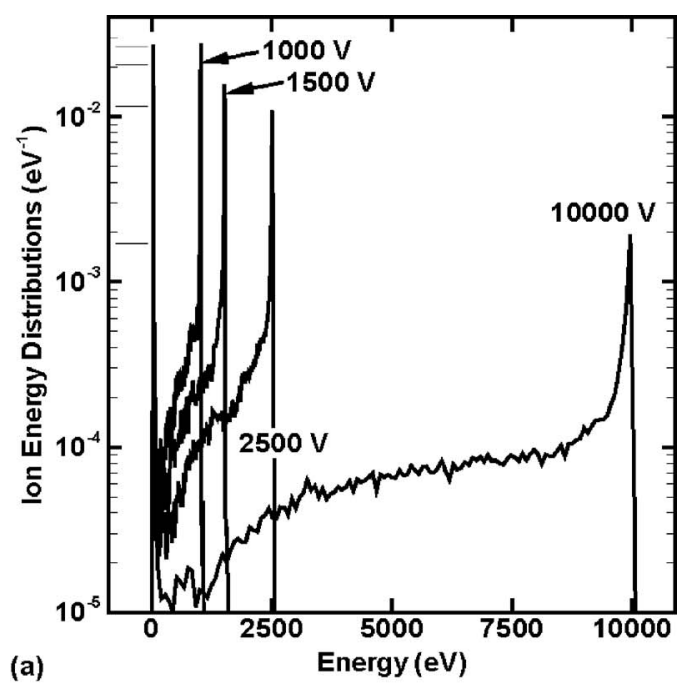

$-10,000 \mathrm{~V}$

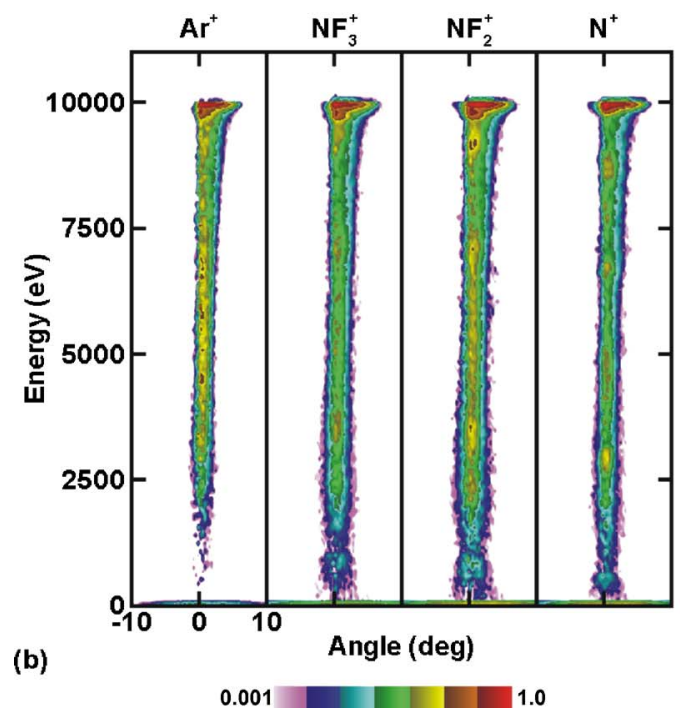

FIG. 8. (Color online) IEADs typically have more prominent tails at higher biases. (a) Ion energy distributions for all ions integrated over angle striking the wafer for different bias voltages. (b) IEADs, averaged over the wafer, for $\mathrm{Ar}^{+}, \mathrm{NF}_{3}{ }^{+}, \mathrm{NF}_{2}{ }^{+}$, and $\mathrm{N}^{+}$ions at base case conditions and $-10000 \mathrm{~V}$ substrate bias. The distributions are plotted over 3 decades to emphasize the tail of the IEADs.

etrates into the middle of the reactor near the ionization source where the electron and ion densities are significantly larger at large radii. At this time, the sheath expansion stalls at larger radii while continuing to penetrate into the lower plasma density in the center of the reactor. The end result is that the sheath is thinner at the large radii.

The rapid switching on of the negative voltage pulse causes the electrons to move rapidly out of the sheath. At the same time positive ions are slowly accelerated in the opposite direction towards the substrate. This rapid charge separation leads to the launching of electrostatic waves which may disrupt the plasma. The electrostatic wave is first evident in the third frame of Fig. 12 and is most prominent (and shown propagating into the plasma) in the fourth frame. The electrostatic waves traverse through the entire reactor, reflecting off the boundaries (as in the fifth frame) before collisionally damping by the end of the voltage pulse (frame 7). 


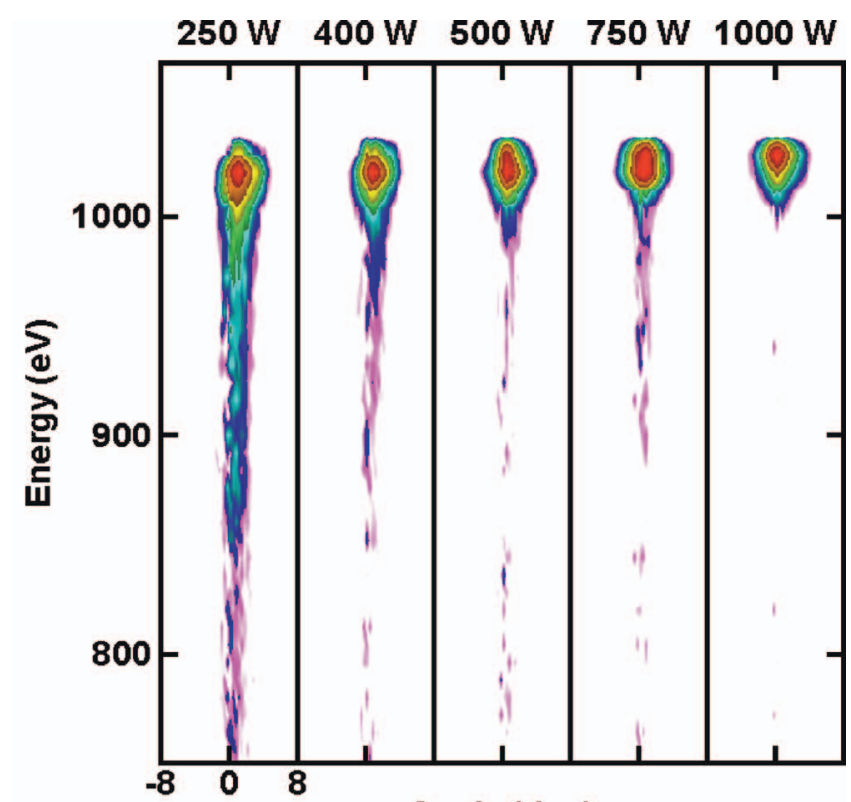

(a)

Angle (deg)

$750 \mathrm{~W}$

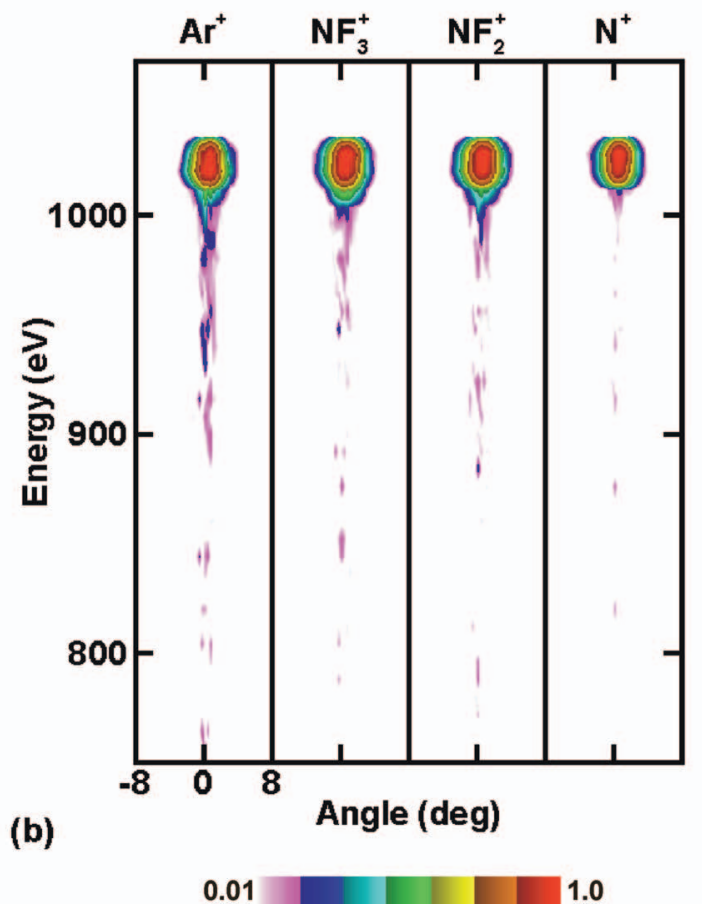

FIG. 9. (Color) Plasma properties as a function of ICP power for otherwise the base case conditions $\left(\mathrm{Ar} / \mathrm{NF}_{3}=80 / 20,500 \mathrm{~W}\right.$ ICP power, $10 \mathrm{mTorr}$, $100 \mathrm{sccm}$ ). (a) IEADs for all ions, averaged over the wafer, for base case conditions with different ICP powers. The tail of the IEAD is less prominent at higher ICP powers due to there being a thinner sheath with less ionization in the sheath. (b) IEADs for $\mathrm{Ar}^{+}, \mathrm{NF}_{3}{ }^{+}, \mathrm{NF}_{2}{ }^{+}$, and $\mathrm{N}^{+}$ions at base case conditions and $750 \mathrm{~W}$ ICP power. Both figures are log scales plotted over 2 decades.

The launching of electrostatic waves is more significant as the bias becomes more negative and the rate of voltage rise increases.

As the voltage pulse terminates, electrons quickly repopulate the sheath so as to recover charge neutrality as the sheath collapses. The sheath properties during this collapse can often be asymmetric. For example, the asymmetry of the

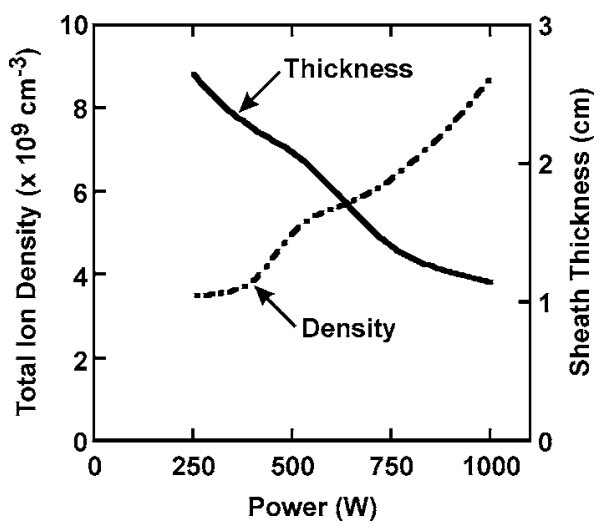

FIG. 10. Total ion density at the edge of the sheath and sheath thickness as a function of ICP power for otherwise the base case conditions $\left(\mathrm{Ar} / \mathrm{NF}_{3}\right.$ $=80 / 20,10 \mathrm{mTorr}, 100 \mathrm{sccm}$ ) for a bias of $-1000 \mathrm{~V}$. The ion densities are measured $0.05 \mathrm{~cm}$ above the sheath at the center of the reactor. Increasing ICP power increases the ion density at the sheath edge and reduces the sheath thickness.

sheath above the substrate is shown in Fig. 13 for different times during the ramp down of the voltage pulse. This period corresponds to the end of the flat-top in the voltage (frame 3) and the rampdown in voltage to zero (frame 8). The electron density is shown for $8 \mathrm{~cm}$ above the substrate. Upon application of the bias, sheath formation proceeds as electrons are expelled from the near substrate volume to form the positive space charge. During the ramp-up period of the pulse, the sheath front propagates into the plasma to unveil more positive space charge to drop the additional voltage. At the end of the flat-top part of the pulse, the sheath has reached a thickness of approximately $7.4 \mathrm{~cm}$ with smaller thickness at large radii. As the voltage is ramped down, the mobile electrons rapidly fill in behind the collapsing sheath, thereby reducing its thickness. The thermal speed of the electrons is large compared to the time rate of the change in sheath thickness, and so the electrons are in quasiequilibrium with the receding sheath. As the sheath collapses, its thickness becomes even less uniform, being thinner near the outer radius where the electron density is larger.

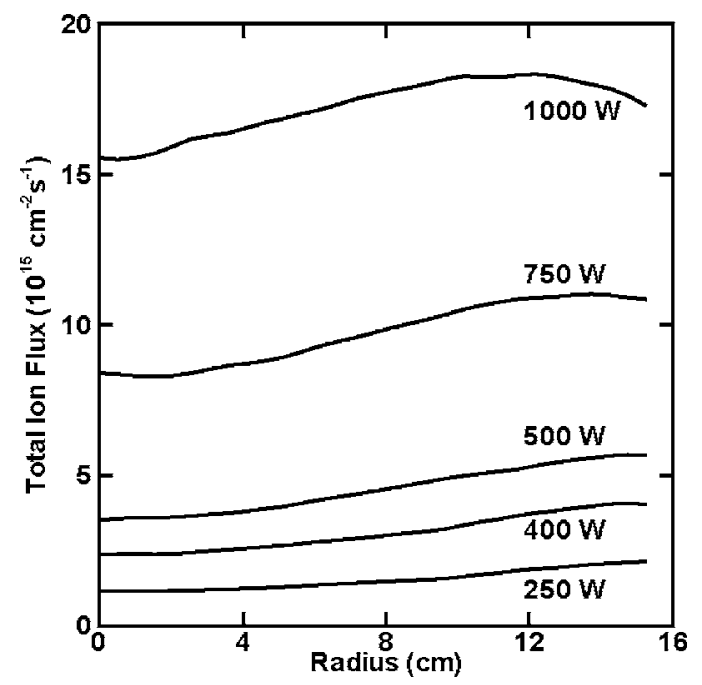

FIG. 11. Total ion flux as a function of radius for otherwise the base case conditions ( $\mathrm{Ar} / \mathrm{NF}_{3}=80 / 20,10 \mathrm{mTorr}, 100 \mathrm{sccm},-1000 \mathrm{~V}$ bias) for different ICP powers. The total ion flux increases with increasing ICP powers with more light ions due to a greater level of dissociation. 
[e] $\operatorname{Max}=6.3 \times 10^{10} \mathrm{~cm}^{-3}$
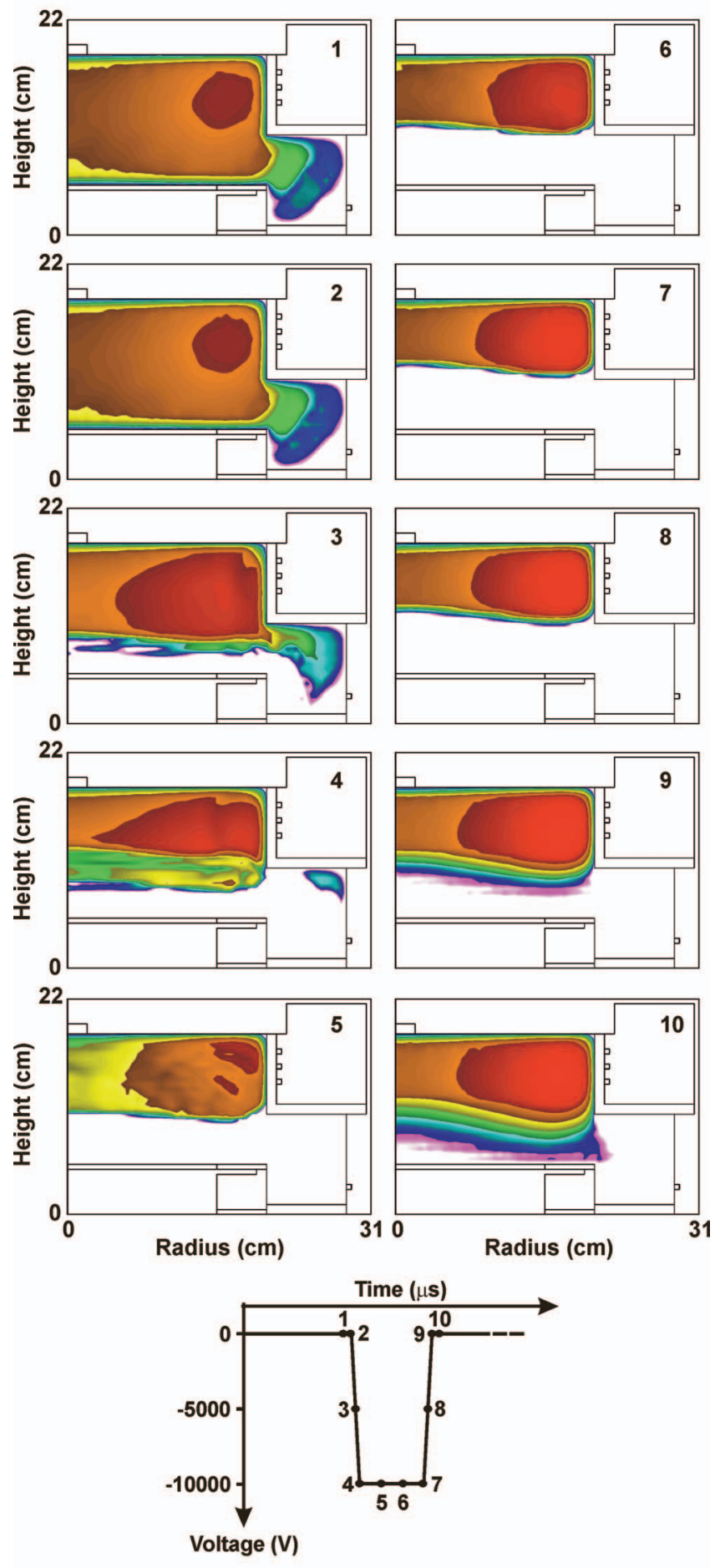

0.01

1.0

FIG. 12. (Color) Electron density for the base case conditions $\left(\mathrm{Ar} / \mathrm{NF}_{3}\right.$ $=80 / 20,500 \mathrm{~W}$ ICP power, $10 \mathrm{mTorr}, 100 \mathrm{sccm})$ and $-10000 \mathrm{~V}$ substrate bias at different times during the pulse (as indicated in the lower figure). The impulsive application of the bias launches electrostatic waves into the plasma. These figures use a $\log$ scale plotted over 2 decades.

The sheath expands deeper into the plasma at higher biases. It also increases its extent into the plasma as the total pulse length increases for a given bias. For example, the electron density is shown in Fig. 14 in the $8 \mathrm{~cm}$ above the substrate for pulse lengths of $10-75 \mu$ s for a bias voltage of [e] $\operatorname{Max}=6.3 \times 10^{10} \mathrm{~cm}^{-3}$
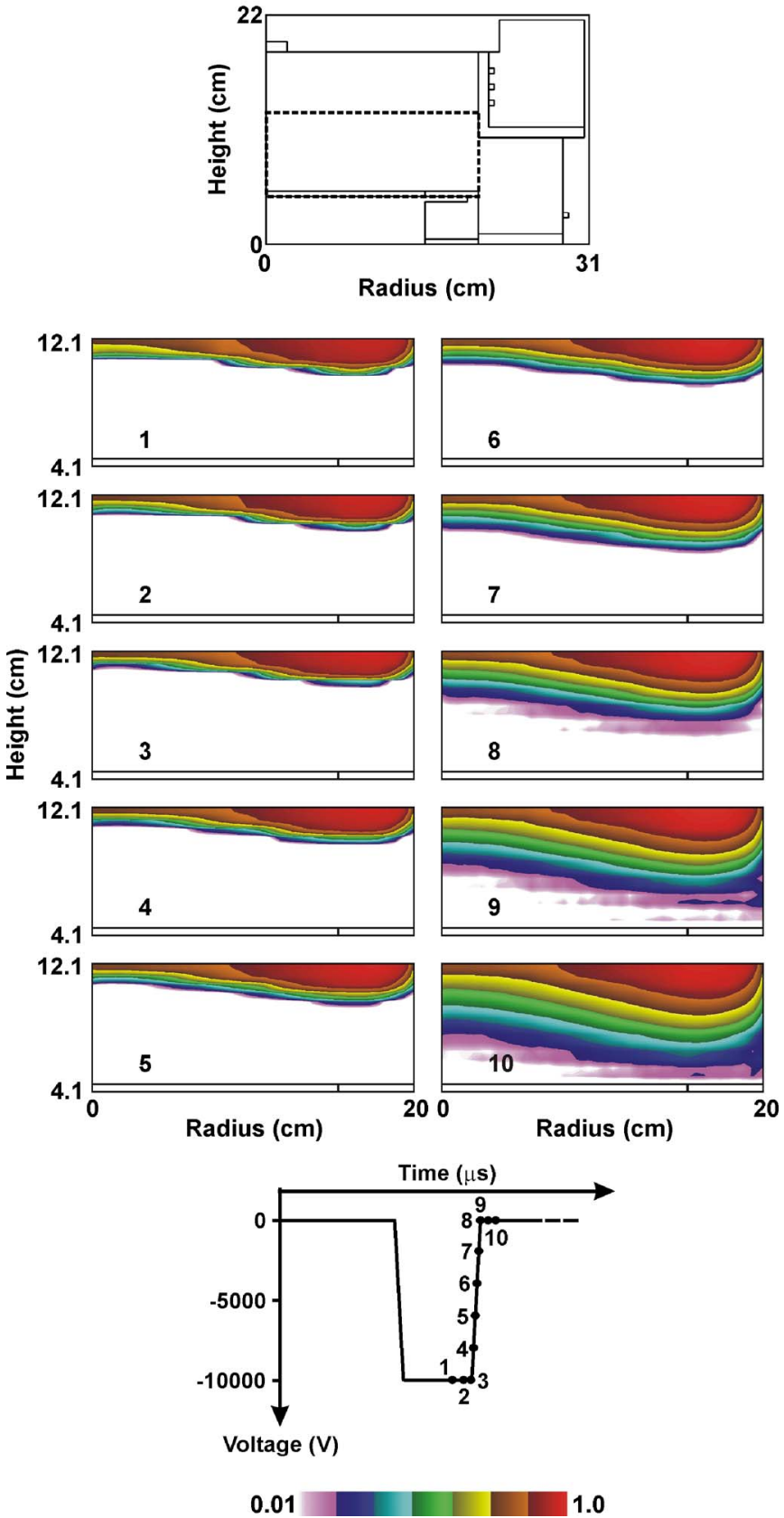

FIG. 13. (Color online) Electron density above the substrate (region indicated in the top frame) as the pulse voltage is ramped down for the base case conditions $\left(\mathrm{Ar} / \mathrm{NF}_{3}=80 / 20,500 \mathrm{~W}\right.$ ICP power, $\left.10 \mathrm{mTorr}, 100 \mathrm{sccm}\right)$ and $-10000 \mathrm{~V}$ substrate bias. The frames are for times indicated in the lower figure. The asymmetry in the sheath is maintained during its collapse. These figures use a log scale plotted over 2 decades.

$-10000 \mathrm{~V}$. The densities are shown at the end of the flat-top part of the voltage pulse. For short pulses $(10 \mu \mathrm{s})$ the sheath appears similar to an ion-matrix sheath where there is not a large change in the ion density due to transport. As a result, the sheath is able to generate enough space charge to drop $-10000 \mathrm{~V}$ over only $4.7 \mathrm{~cm}$. As the pulse length increases, there is depletion of the ion density in the sheath, thereby resulting in an extension of the sheath into the plasma, expelling electrons from a larger volume to produce more positive charge. A steady state is achieved only when the flux of 


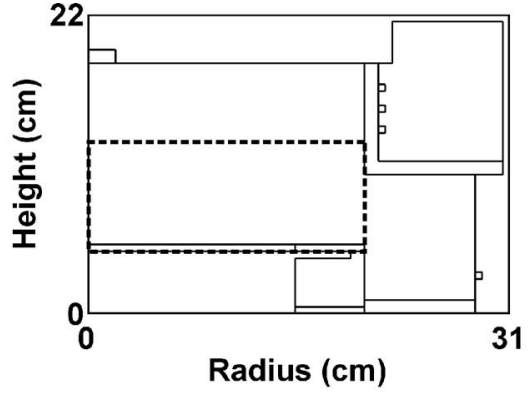

$\operatorname{Max}=5.5 \times 10^{10} \mathrm{~cm}^{-3}$
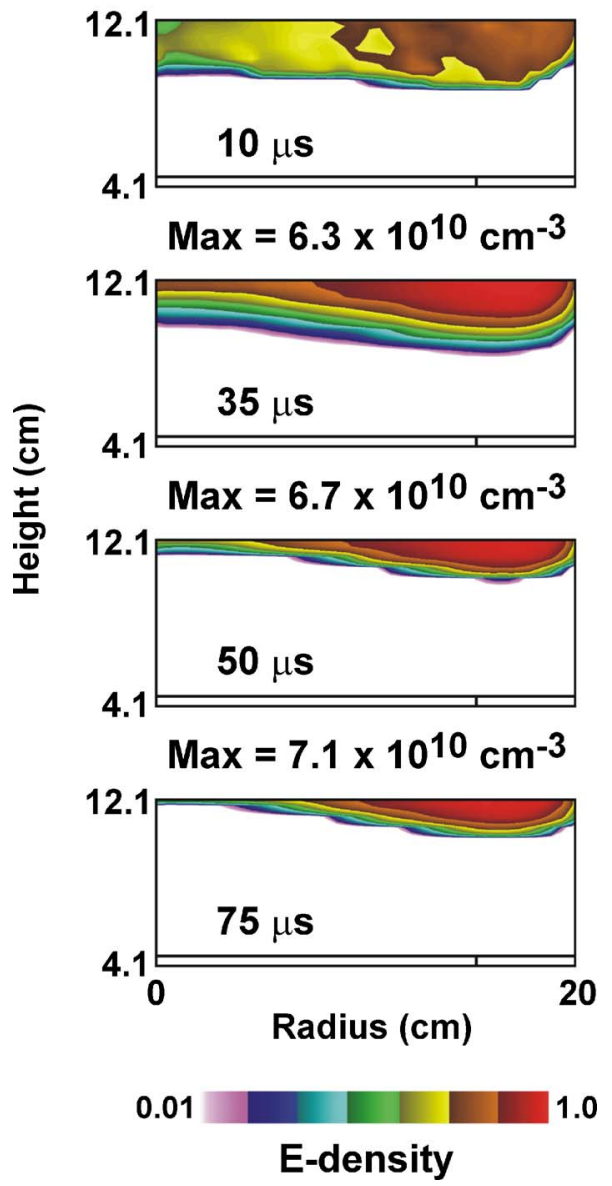

FIG. 14. (Color online) Electron density above the substrate (region indicated in the top frame) at the end of the constant portion of the substrate voltage pulse for different pulse lengths. The results are otherwise for base case conditions $\left(\mathrm{Ar} / \mathrm{NF}_{3}=80 / 20,500 \mathrm{~W}\right.$ ICP power, $\left.10 \mathrm{mTorr}, 100 \mathrm{sccm}\right)$ and $-10000 \mathrm{~V}$ substrate bias. The sheath thickness increases with increasing pulse length as positive charge in the sheath is depleted by flow into the cathode. These figures use a log plotted over 2 decades.

ions into the sheath equals the ion flux into the substrate. This steady state is achieved for pulse lengths $>50 \mu \mathrm{s}$. For the IEADs to be as uniform as possible throughout the voltage pulse, the majority of the ion flux through the sheath should be collected under quasi-steady-state conditions. Using this criterion, for a bias of $-10000 \mathrm{~V}$ the pulse length should be $>50 \mu \mathrm{s}$.

The ionization produced by secondary electrons emitted from the substrate for a bias voltage of $-10000 \mathrm{~V}$ is shown in Fig. 15, at different times during the pulse between prior to application of bias (frame 1) until after the end of the voltage pulse (frame 10). The transit of electrons through the

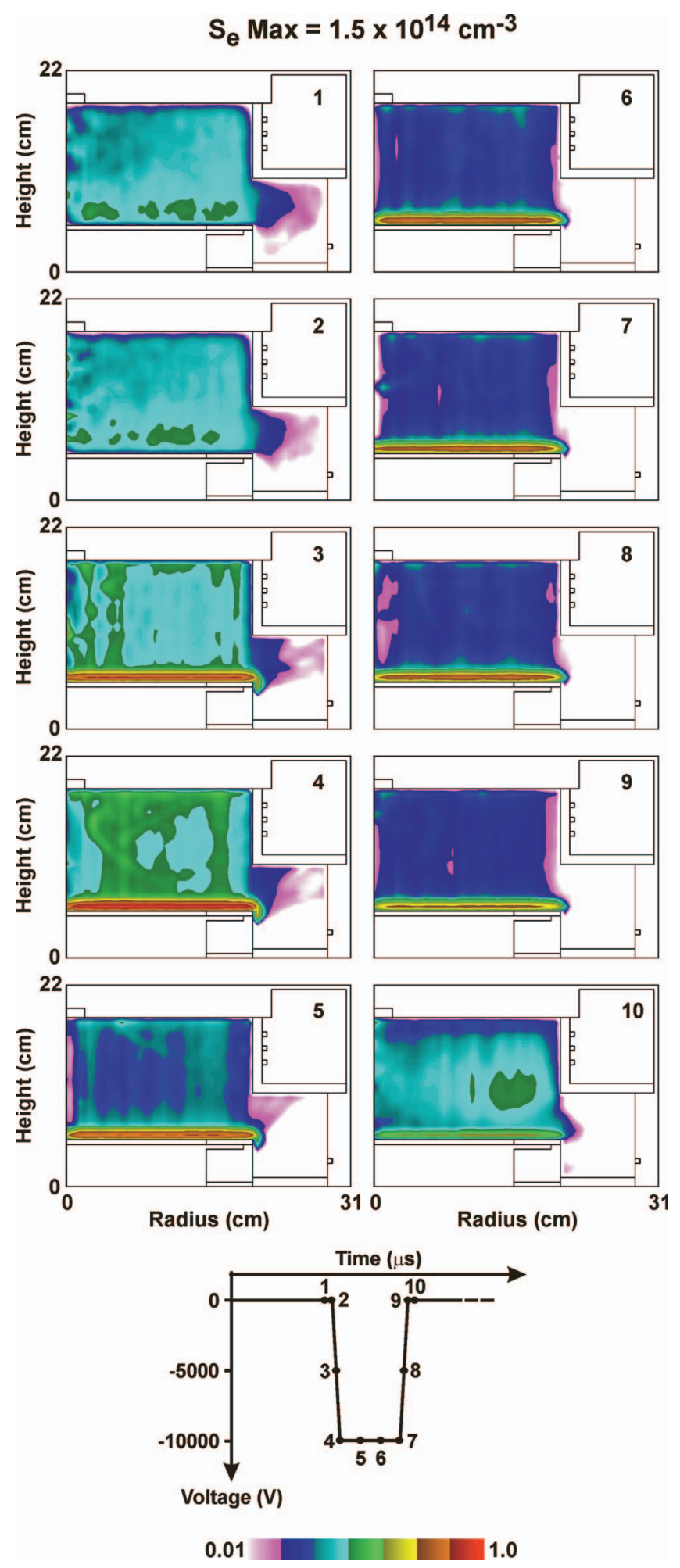

FIG. 15. (Color) Ionization produced by the secondary electrons emitted from the substrate and accelerated by the sheath at different times during the pulse (as indicated in the lower figure). The conditions are the base case (Ar $/ \mathrm{NF}_{3}=80 / 20,500 \mathrm{~W}$ ICP power, $10 \mathrm{mTorr}, 100 \mathrm{sccm}$ ) and $-10000 \mathrm{~V}$ substrate bias. The secondary electron emission coefficient varies with incident ion energy. Ionization is maximum in the sheath when electrons pass through the maximum cross section. Figure uses a log scale plotted over 2 decades.

sheath borders on being collisionless, resulting in significant secondary electron current being collected by the top surface of the reactor, though clearly collisions occur to produce 
these ionization sources. The peak energy of the electrons as they transit the sheath is nearly equal to the instantaneous sheath potential. The maximum in the ionization cross section for Ar is approximately $100 \mathrm{eV}$ and for $\mathrm{NF}_{3}$ is $90 \mathrm{eV}$. When the sheath potential is low prior to the bias pulse (25-30 eV prior to frame 2) the ionization by secondary electrons is low and their range through the plasma is roughly half the height of the reactor due largely to nonionizing collisions. As the bias is gradually increased to its flattop value (frame 2 to frame 4), the secondary electron energy leaving the sheath increases up to $10000 \mathrm{eV}$, an energy above the maximum for ionization. The maximum ionization source occurs in the sheath when the beam electrons pass through the maximum in the ionization cross section. As electron energies increase above $90-100 \mathrm{eV}$, their mean free path lengthens, thereby producing a low source of ionization that extends across the reactor. In fact, the majority of the electron flux penetrates through the reactor and impacts on the top metal plate. As the bias voltage ramps down (corresponding to frames 7-10), the energy of the secondary electron beam energy also decreases, passing through the maximum in the ionization cross section and producing a momentary maximum in ionization.

The yield of secondary electrons per ion varies greatly with the ion energy and the surface the ion strikes. ${ }^{21}$ For these conditions, the yield per ion increases at energies above $3000 \mathrm{eV}$. At higher biases, the increase in secondary electron yield and secondary electron current as the sheath voltage increases somewhat compensates for the decrease in ionization cross section at higher electron energies.

We have observed in many instances a pulsation effect in which islands of plasma are ejected through the gap between the upper dielectric structure and the focus ring. This sequence of the plasma ejection is shown by the $\mathrm{NF}_{2}{ }^{+}$and $\mathrm{F}^{-}$ densities appearing in Figs. 16 and 17 for a bias voltage of $-10000 \mathrm{~V}$. Densities are shown at different times beginning early in the bias pulse (frame 1), through the interpulse period and ending with just prior to the following voltage pulse (frame 10). The peak $\mathrm{NF}_{2}^{+}$density, $1.8 \times 10^{10} \mathrm{~cm}^{-3}$, occurs near the source of production adjacent to the coils. The peak $\mathrm{F}^{-}$density, $3.1 \times 10^{10} \mathrm{~cm}^{-3}$, occurs in the same location, which is also where the plasma potential is maximum. (The dominant positive ion is $\mathrm{Ar}^{+}$.) In the absence of pulsing the bias, the plasma is essentially continuous through the gap between the upper dielectric structure and the focus ring. As the bias is applied, the sheath expands bringing with it a large negative plasma potential. Negative ions (and electrons) are accelerated out of this region which pinches off an island of plasma in the periphery of the reactor. (On the outer radius of the substrate, the majority of the applied voltage is dropped across the focus ring and so the sheath thickness is smaller.) The electron temperature is low in the periphery and so electron attachment rapidly occurs, resulting in the plasma being dominated by negative ions. This plasma island is somewhat stabilized by the negative ions being trapped in a local maximum in plasma potential that occurs in the periphery of the reactor. Ambipolar electric fields provide a net

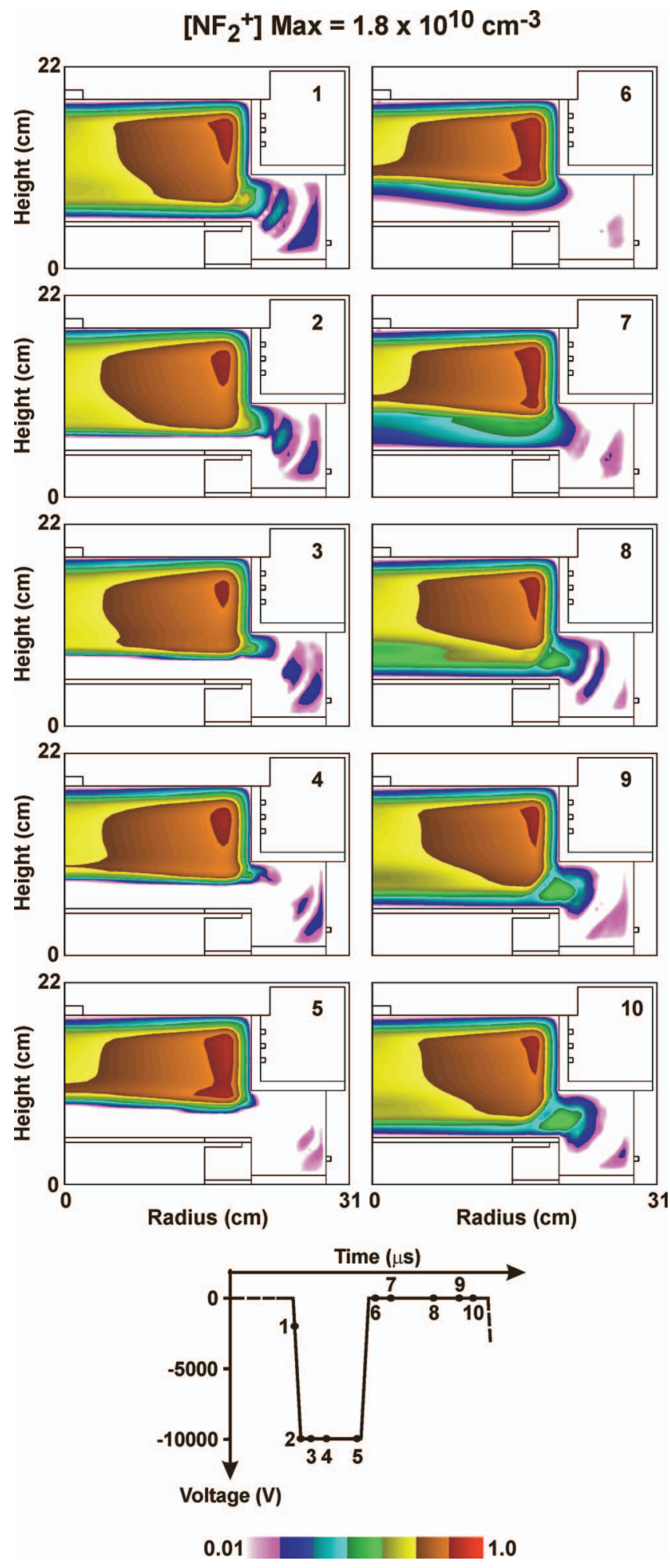

FIG. 16. (Color) $\mathrm{NF}_{2}{ }^{+}$density for the base case conditions $\left(\mathrm{Ar} / \mathrm{NF}_{3}\right.$ $=80 / 20,500 \mathrm{~W}$ ICP power, $10 \mathrm{mTorr}, 100 \mathrm{sccm}$ ) and $-10000 \mathrm{~V}$ substrate bias during the pulse and interpulse period (as shown in the lower figure). The varying thickness of the sheath (thicker above the substrate and thinner above the focus ring) results in isolation of an island of positive ions in the periphery of the reactor. Figure uses a log scale plotted over 2 decades.

outward force on the plasma island while negative ionpositive ion recombination depletes the density in the plasma island.

When the bias pulse is terminated, the sheath shrinks and plasma extends towards the gap. Plasma then flows into the 
$\left[F^{-}\right] \operatorname{Max}=3.1 \times 10^{11} \mathrm{~cm}^{-3}$
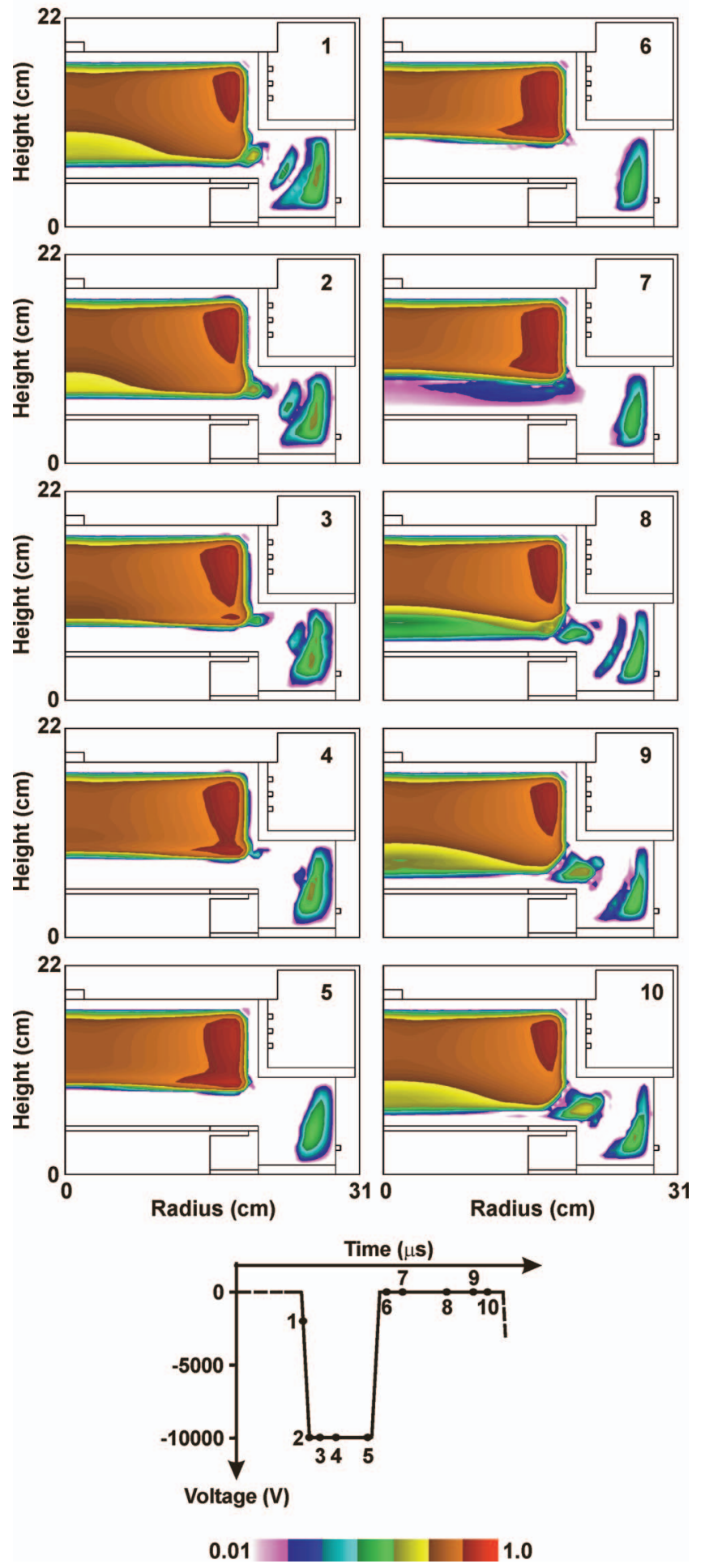

FIG. 17. (Color) $\mathrm{F}^{-}$density for the base case conditions $\left(\mathrm{Ar} / \mathrm{NF}_{3}=80 / 20\right.$, $500 \mathrm{~W}$ ICP power, $10 \mathrm{mTorr}, 100 \mathrm{sccm})$ and $-10000 \mathrm{~V}$ substrate bias during the pulse and interpulse period (as shown in the lower figure). The negative ions trapped in the local maximum in plasma potential contribute to the stability of the islands of positive ions in the periphery of the reactor. Figure uses a log scale plotted over 2 decades.

periphery of the reactor. If the sheath is thin and interpulse period short, the plasma flow may connect with a nearby island. If the sheath is thick and interpulse period long, the prior plasma island has drifted far and the reinitiated plasma flow may seed a new island. The repetitive pulsing of the bias then gives the appearance of successive islands of plasma being ejected through the gap.

The formation of the islands is facilitated by the rapid negative ion formation afforded by the thermal attachment cross section of $\mathrm{NF}_{3}$. The electron temperature drops from $4.8 \mathrm{eV}$ in the bulk plasma to $4.1 \mathrm{eV}$ in the periphery of the reactor. This decrease in electron temperature takes the plasma from having net positive ionization in the bulk to being attachment dominated in the periphery.

\section{THE EFFECT OF REACTOR DESIGN ON SYMMETRY OF IEADS}

For this particular reactor configuration, ions are dominantly produced at larger radii near the coils and diffuse towards the wafer. These ions approach the sheath with velocities preferentially oriented towards the axis. At low bias voltages, the sheath is thin and fairly uniform, and the majority of the reactor is occupied by plasma, as shown in Fig. $3(\mathrm{c})$. As a result, the ions have sufficient time while they transport from their source to the sheath edge to reorient their velocities to be nearly perpendicular to the substrate. Since the sheath thickness is uniform and parallel to the substrate, after acceleration through the sheath, the angular distribution of the ions incident onto the wafer is symmetric, as shown by the IEADs in Fig. 6(a) for a bias voltage of $V_{o}=-1.0 \mathrm{kV}$.

As the bias voltage increases and the sheath extends far into the plasma, it impinges onto that portion of the reactor where there is a significant variation in plasma density, lower on the axis and higher at a large radius. The sheath thickness, which scales inversely with plasma density, therefore becomes larger at a small radius and smaller at a larger radius. This produces a gradient to the sheath thickness across the reactor. At the same time, a smaller fraction of the volume of the reactor is plasma (as opposed to the sheath), providing less opportunity for ions that are preferentially produced off axis and have a large radial component to their velocity to reorient their velocities to a more axial direction. The ions entering the sheath with an off-axis velocity are initially accelerated perpendicular to the sheath edge which is not parallel to the substrate. Although the electric field in the sheath eventually does become perpendicular to the substrate, the perpendicular electric field is not large enough to offset the inwardly axial velocity of the ions produced in the first portion of the sheath. The end result is that these ions arrive at the wafer with an asymmetric angular distribution which is skewed to one side, as shown in Fig. 6(a) for a bias voltage of $V_{o}=-10 \mathrm{kV}$.

For the ions to arrive at the substrate with a symmetric angular distribution, the ions should ideally enter the sheath with axially oriented velocities and the sheath should be parallel to the substrate (that is, the electric field in the sheath is perpendicular to the substrate) or the voltage drop in the portion of the sheath which is not parallel to the substrate should be a small fraction of the total. The parallel nature of the sheath is determined, in part, by the uniformity of the plasma into which the sheath is propagating. The uniformity of the plasma is determined by the location of the ionization sources and transport of the charged species after ionization. 

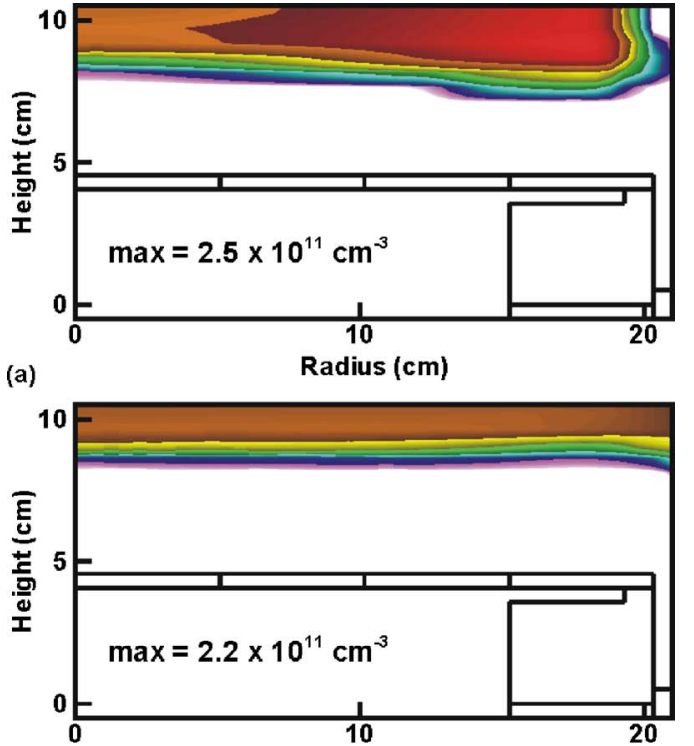

(b)

Radius (cm)

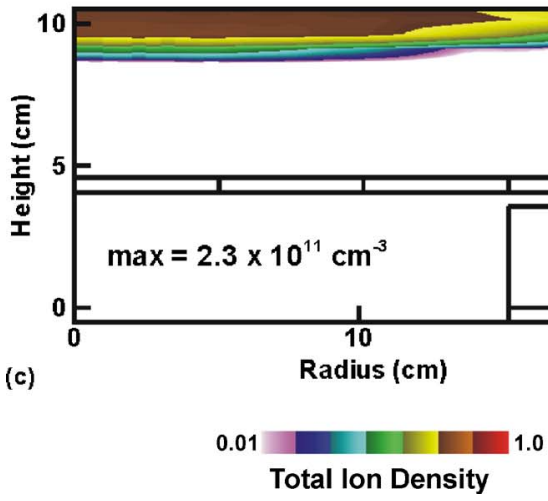

FIG. 18. (Color online) Total ion density for the base case conditions $\left(\mathrm{Ar} / \mathrm{NF}_{3}=80 / 20,500 \mathrm{~W}\right.$ ICP power, $\left.10 \mathrm{mTorr}, 100 \mathrm{sccm}\right)$ and $-10000 \mathrm{~V}$ substrate bias at the end of the constant portion of the substrate voltage pulse for increasing height of the reactor. (a) 22 , (b) 30 , and (c) $35 \mathrm{~cm}$. As the height of the reactor increases, the sheath transitions from being thinner at the outer radius to being thinner at the inner radius. Figures use a log scale plotted over 2 decades.

Due to the need for the top of the reactor to be metal to collect the secondary electron flux that penetrates across the reactor with large biases, there is limited freedom in choosing the location of the coils that determine the location of ionization sources. The shape of the reactor can, however, be used to change the uniformity of the plasma and so the angular symmetry of the IEADs.

For example, the height of the reactor was increased from 22 to $35 \mathrm{~cm}$ while keeping the radius constant. The total ion density is shown in Fig. 18 in the vicinity of the substrate for base case conditions with a bias voltage of $-10000 \mathrm{~V}$. IEADs incident on axis, mid-radius, and on the outer radius of the wafer for these conditions are shown in Fig. 19. As the height of the reactor is increased, the plasma density transitions from being largest in the periphery of the reactor to assuming a more diffusion dominated shape emphasizing the center of the reactor. As such, as the height of the reactor increases, the sheath thickness transitions from being thinnest on the outer periphery, as shown in Fig. 18(a), to being thinnest on the axis, as shown in Fig. 18(c). The
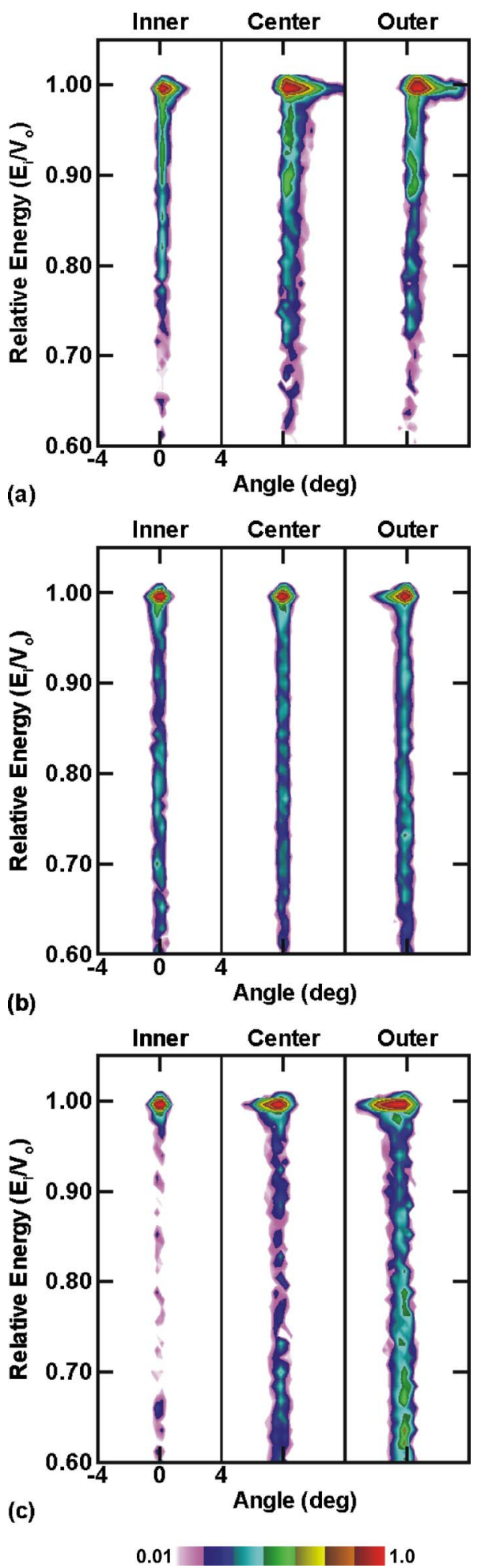

FIG. 19. (Color online) Total ion energy and angular distributions at different radial positions along the wafer for increasing height of the reactor. (a) 22, (b) 30 , and (c) $35 \mathrm{~cm}$. The IEADs transition from being angularly skewed inward (short reactor) to being angularly skewed outward (tall reactor). Figures use a $\log$ scale plotted over 2 decades.

angular symmetry of the IEADs reflects the change in the direction of the gradient of the sheaths as the height of the reactor increases. For the short reactor with a thin sheath at large radius [Fig. 18(a)], the skew in the IEAD is to positive angle [Fig. 19(a)] and is most severe at a large radius. For the tall reactor with the sheath thinner at a smaller radius [Fig. 


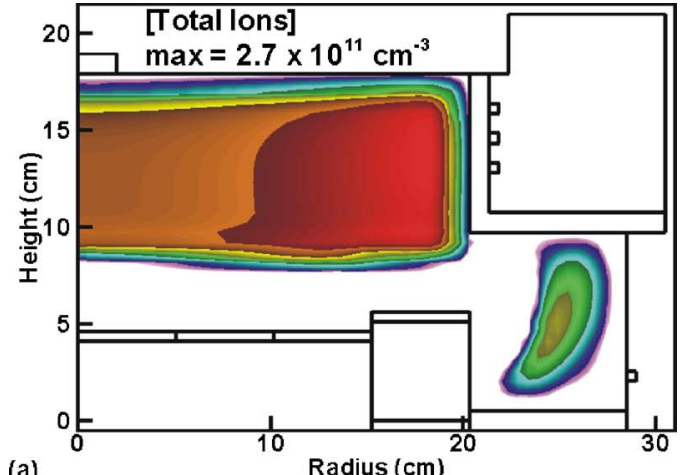

(a)

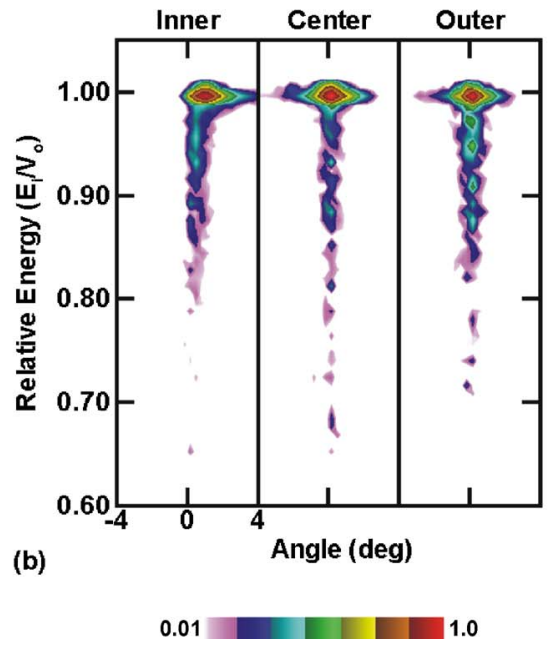

FIG. 20. (Color online) Plasma characteristics for a reactor with a raised focus ring. (a) Total ion density when the bias is $-10000 \mathrm{~V}$. (b) IEADs for the inner, middle, and outer regions of the wafer. The focus ring produces a more uniform sheath and so more symmetric IEADs. These figures use a log scale plotted over 2 decades.

18(c)], the skew in the IEAD is towards a negative angle [Fig. 19(c)]. The intermediate height reactor having the most uniform sheath thickness has the most angularly symmetric IEADs.

Small modifications to the original reactor can also affect the uniformity of the sheath thickness and so the angular symmetry of the IEADs. For example, the height of the focus ring outside the wafer was increased by about $1 \mathrm{~cm}$. The resulting total ion density and IEADs are shown in Fig. 20 for base case conditions with a bias voltage of $-10000 \mathrm{~V}$. The higher focus ring produces a fairly uniform sheath that is slightly thicker at a large radius which compensates for the inward trajectories of ions as they approach the sheath. The end result is that the IEADs are more angular symmetric with the elevated focus ring that with a flat focus ring.

\section{CONCLUDING REMARKS}

The characteristics of inductively coupled reactors for pulsed plasma doping of semiconductors were computationally investigated. We found that the IEADs of ions incident on the wafer are sensitive functions of the ICP power deposition and bias pulse shape. The ideal IEAD is angularly symmetric and monoenergetic. Plasma conditions that produce thick sheaths for an extended period during the bias (e.g., low ICP power producing low ion density or large bias voltage) produce low energy tails to the IEADs resulting from ionization that occurs in the sheath by secondary electrons. Since the sheath can extend many centimeters into the plasma, the uniformity of the plasma far from the substrate is important. Gradients in the thickness of the sheath may produce angularly asymmetric IEADs. The angular symmetry can be controlled through the shape of the reactor or modifications such as the height of the focus ring that decrease the gradient in the sheath thickness across the wafer.

\section{ACKNOWLEDGMENTS}

The authors thank Varian Semiconductor Equipment Associates, the Semiconductor Research Corporation, and the National Science Foundation (CTS-0520368) for their support of this work. The authors particularly thank Dr. Rajesh Dorai for his guidance during this investigation.

${ }^{1}$ International Technology Roadmap for Semiconductors-Semiconductor Industry Association (http://public.itrs.net/Files/2003ITRS/ Home2003.htm), 2003.

${ }^{2}$ Q. L. Zhang, C. Tang, T. Hsieh, N. Maccrae, B. Singh, K. Poolla and C. J. Spanos, Proc. SPIE 5372, 692 (2005).

${ }^{3}$ G. D. Wilk, R. M. Wallace, and J. M. Anthony, J. Appl. Phys. 89, 5243 (2001).

${ }^{4}$ S. Walther and R. Liebert, J. Vac. Sci. Technol. B 24, 482 (2006).

${ }^{5}$ D. A. Brown and J. F. O'Hanlon, Phys. Rev. E 48, 523 (1996).

${ }^{6}$ A. Renau and J. T. Scheuer, Proceedings of the 14th International Conference on Ion Implant Tech (IEEE, New York, 2002), p. 151.

${ }^{7}$ G. Angel, E. Bell, D. Brown, J. Buff, J. Cummings, W. Edwards, C. McKenna, S. Radovanov, and N. R. White, Proceedings of the 12th International Conference on Ion Implant Tech (IEEE, New York, 1998), p. 188. ${ }^{8}$ H. Sundstrom, V. Benveniste, M. Graf, W. Krull, F. Sinclair, and T. Kinney, Proceedings of the 12th International Conference on Ion Implant Tech (IEEE, New York, 1998), p. 184.

${ }^{9} \mathrm{P}$. Edwards et al., Proceedings of the 12th International Conference on Ion Implant Tech (IEEE, New York, 1998), p. 362.

${ }^{10}$ J. A. van den Berg, G. Wostenholm, M. Geryk, and D. G. Armour, Proceedings of the 13th International Conference on Ion Implant Tech (IEEE, New York, 2000), p. 627.

${ }^{11}$ P. K. Chu, S. Qin, C. Chan, N. W. Cheung, and L. A. Larson, Mater. Sci. Eng., R. 17, 207 (1996).

${ }^{12}$ S. B. Felch, Z. Fang, B.-W. Koo, R. B. Liebert, S. R. Walther, and D. Hacker, Surf. Coat. Technol. 156, 229 (2002).

${ }^{13}$ R. J. Matyi, D. L. Chapek, D. P. Brunco, S. B. Felch, and B. S. Lee, Surf. Coat. Technol. 93, 247 (1997).

${ }^{14}$ S. B. Felch, B. S. Lee, S. L. Daryanani, D. F. Downey, and R. J. Matyi, Mater. Chem. Phys. 54, 37 (1998).

${ }^{15}$ M. J. Goeckner, S. B. Felch, Z. Fang, D. Lenoble, J. Galvier, A. Grouillet, G. C.-F. Yeap, D. Bang, and M.-R. Lin, J. Vac. Sci. Technol. A 17, 2290 (1999).

${ }^{16}$ J. T. Scheuer et al., Surf. Coat. Technol. 186, 57 (2004).

${ }^{17}$ D. Vempaire, J. Pelletier, A. Lacoste, S. Béchu, J. Sirou, S. Miraglia, and D. Fruchart, Plasma Phys. Controlled Fusion 47, A153 (2005).

${ }^{18}$ A. Agarwal and M. J. Kushner, IEEE Trans. Plasma Sci. 33, 252 (2005).

${ }^{19}$ R. L. Kinder and M. J. Kushner, J. Appl. Phys. 90, 3699 (2001).

${ }^{20}$ R. L. Kinder and M. J. Kushner, J. Vac. Sci. Technol. A 19, 76 (2001).

${ }^{21}$ A. V. Phelps and Z. L. Petrović, Plasma Sources Sci. Technol. 8, R21 (1999).

${ }^{22}$ Y. Chutopa, B. Yotsombat, and I. G. Brown, IEEE Trans. Plasma Sci. 31, 1095 (2003).

${ }^{23}$ K. Ohya, Nucl. Instrum. Methods Phys. Res. B 153, 58 (1999).

${ }^{24}$ K. Ohya, Nucl. Instrum. Methods Phys. Res. B 206, 52 (2003).

${ }^{25}$ M. M. Shamim, J. T. Scheuer, R. P. Fetherston, and J. R. Conrad, J. Appl. Phys. 70, 4756 (1991).

${ }^{26}$ W. En and N. W. Cheung, IEEE Trans. Plasma Sci. 24, 1184 (1996).

${ }^{27}$ M. Hayashi, Nagoya Institute of Technology Report No. IPPJ-AM-19 (Research Information Center, IPP/Nagoya University, Nagoya, Japan, 1981).

${ }^{28}$ K. Tachibana, Phys. Rev. A 34, 1007 (1986).

${ }^{29}$ D. Rapp and P. Englander-Golden, J. Chem. Phys. 43, 1464 (1965). 
${ }^{30}$ R. H. McFarland and J. D. Kinney, Phys. Rev. 137, 1058 (1965).

${ }^{31}$ T. N. Rescigno, Phys. Rev. A 52, 329 (1995).

${ }^{32}$ E. Meeks, R. S. Larson, S. R. Vosen, and J. W. Shon, J. Electrochem. Soc. 144, 357 (1997); E. Meeks (private communication).

${ }^{33}$ S. Ushiroda, S. Kajita, and Y. Kondo, J. Phys. D 23, 47 (1990).

${ }^{34}$ V. Tarnovsky, A. Levin, K. Becker, R. Basner, and M. Schmidt, Int. J. Mass Spectrom. Ion Process. 133, 175 (1994).

${ }^{35}$ K. E. Greenberg and J. T. Verdeyen, J. Appl. Phys. 57, 1596 (1985).

${ }^{36}$ M. Hayashi and T. Nimura, J. Appl. Phys. 54, 4879 (1983).

${ }^{37}$ W. L. Morgan, Adv. At., Mol., Opt. Phys. 43, 79 (2000).

${ }^{38}$ T. R. Hayes, R. C. Wetzel, and R. S. Freund, Phys. Rev. A 35, 578 (1987).

${ }^{39}$ A. V. Phelps and L. C. Pitchford, Phys. Rev. A 31, 2932 (1985).

${ }^{40}$ D. C. Cartwright, S. Trajmar, A. Chutjian, and W. Williams, Phys. Rev. A 16, 1041 (1977).

${ }^{41}$ W. L. Borst, Phys. Rev. A 5, 648 (1972).

${ }^{42}$ R. T. Brinkmann and S. Trajmar, Ann. Geophys. (C.N.R.S.) 26, 201 (1970).

${ }^{43}$ L. Vriens, Phys. Lett. 8, 260 (1964).

${ }^{44}$ A. V. Phelps, J. Phys. Chem. Ref. Data 20, 557 (1991).

${ }^{45}$ S. Geltman, J. Quant. Spectrosc. Radiat. Transf. 13, 601 (1973).

${ }^{46}$ R. J. W. Henry, P. G. Burke, and A.-L. Sinfailam, Phys. Rev. 178, 218 (1969).

${ }^{47}$ A. C. H. Smith, E. Caplinger, R. H. Neynaber, E. W. Rothe, and S. M. Trujillo, Phys. Rev. 127, 1647 (1962).

${ }^{48}$ A. N. Klucharev and V. Vujnovic, Phys. Rep. 185, 55 (1990).

${ }^{49}$ L. G. Piper, J. E. Velazco, and D. W. Setser, J. Chem. Phys. 59, 3323 (1973).

${ }^{50}$ J. E. Velazco, J. H. Kolts, and D. W. Setser, J. Chem. Phys. 65, 3468 (1976).

${ }^{51}$ R. J. Shul, R. Passarella, B. L. Upschulte, R. G. Keesee, and A. W. Castleman, Jr., J. Chem. Phys. 86, 4446 (1987).

${ }^{52}$ T. M. Miller, J. F. Friedman, A. E. S. Miller, and J. F. Paulson, J. Phys. Chem. 98, 6144 (1994).

${ }^{53}$ G. I. Font, W. L. Morgan, and G. Mennenga, J. Appl. Phys. 91, 3530
(2002).

${ }^{54}$ M. Hamdan, N. W. Copp, K. Birkinshaw, J. D. C. Jones, and N. D. Twiddy, Int. J. Mass Spectrom. Ion Process. 69, 191 (1986).

${ }^{55}$ D. Smith, N. G. Adams, and T. M. Miller, J. Chem. Phys. 69, 308 (1978).

${ }^{56}$ E. E. Ferguson, Adv. Electron. Electron Phys. 24, 1 (1968).

${ }^{57}$ S. A. Sullivan and J. L. Beauchamp, Inorg. Chem. 17, 1589 (1978).

${ }^{58}$ P. B. Armentrout, D. W. Berman, and J. L. Beauchamp, Chem. Phys. Lett. 53, 255 (1978).

${ }^{59}$ R. E. Olson, J. R. Peterson, and J. Moseley, J. Chem. Phys. 53, 3391 (1970).

${ }^{60}$ A. C. Lloyd, Int. J. Chem. Kinet. 3, 39 (1971).

${ }^{61}$ J. B. Koffend, C. E. Gardner, and R. F. Heidner, J. Chem. Phys. 83, 2904 (1985).

${ }^{62}$ V. N. Kondratiev, Rate Constants of Gas Phase Reactions (COM-7210014) (U.S. Department of Commerce, Washington, DC, 1972).

${ }^{63}$ B. H. Weiller, R. F. Heidner, J. S. Holloway, and J. B. Koffend, J. Phys. Chem. 96, 9321 (1992).

${ }^{64}$ C. T. Cheah, M. A. A. Clyne, and P. D. Whitefield, J. Chem. Soc., Faraday Trans. 2 76, 711 (1980).

${ }^{65}$ V. B. Rozenshtein, Y. R. Bedzhanyan, and Y. M. Gershenson, Kinet. Catal. 29, 22 (1988).

${ }^{66}$ M. F. Golde, Int. J. Chem. Kinet. 20, 75 (1988).

${ }^{67}$ L. G. Piper, J. Chem. Phys. 87, 1625 (1987).

${ }^{68}$ J. C. Person and D. O. Ham, Radiat. Phys. Chem. 31, 1 (1988).

${ }^{69}$ J. A. Kerr and S. J. Moss, CRC Handbook of Biomolecular and Trimolecular Gas Reactions (CRC, Boca Raton, FL, 1981).

${ }^{70}$ L. G. Piper, J. Chem. Phys. 88, 231 (1988).

${ }^{71}$ Y. Ikezoe, S. Matsuoka, M. Takebe, and A. Viggiano, Gas Phase Ion Molecule Reaction Rate Constants Through 1986 (Ion Reaction Research Group, Tokyo, Japan, 1987).

${ }^{72}$ J. A. Stittsworth and A. E. Wendt, Plasma Sources Sci. Technol. 5, 429 (1996).

${ }^{73}$ W. Ensinger, Mater. Sci. Eng., A 253, 258 (1998). 